\title{
Science Inside Law: The Making of a New Patent Class in the International Patent Classification
}

\section{Hyo Yoon Kang}

University of Lucerne

E-mail:hyo.kang@unilu.ch

\section{Argument}

Recent studies of patents have argued that the very materiality and techniques of legal media, such as the written patent document, are vital for the legal construction of a patentable invention. Developing the centrality placed on patent documents further, it becomes important to understand how these documents are ordered and mobilized. Patent classification answers the necessity of making the virtual nature of textual claims practicable by linking written inscription to bureaucracy. Here, the epistemological organization of documents overlaps with the grid of patent administration. How are scientific inventions represented in such a process? If we examine the process of creating a new patent category within the International Patent Classification (IPC), it becomes clear that disagreements about the substance of the novel inventive subject matter have been resolved by computer simulations of patent documents in draft classifications. The practical needs of patent examiners were the most important concerns in the making of a new category. Such a lack of epistemological mediation between the scientific and legal identities of an invention depicts a legal understanding that science is already inside patent law. From an internal legal perspective, the self-referential introduction of the new patent category may make practical sense; however it becomes problematic from a technological and scientific standpoint as the remit of the patent classification also affects other social contexts and practices.

\section{Introduction}

Classification goes to the heart of the problem of movement of knowledge. It constitutes the primary technique by which knowledge is identified, distinguished, and ordered across different domains (Durkheim and Mauss [1903] 1967; Douglas and Hull 1992). A class or category necessarily entails multiple identities and interpretations (Star and Bowker 1999, 290). In this article on International Patent Classification (IPC), I analyze the way patent law identifies, represents, and orders technoscientific novelties, and the effects of such practice. Whereas scientific novelty has been conceived by historians of science as a product of technical "realization" of a potentiality (Bachelard [1934] 1988, 11) or "contained excess" (Rheinberger 1997, 183) inherent in a specific and contingent set of material scientific practices, the transposition of scientific novelty into patent law requires its own genealogy by its reference to a legal past. This is done through 
a patent classification system that categorizes and organizes past patents and patentpending inventions. The IPC lends legal visibility and identity to technoscientific objects by forming an epistemic, administrative, and temporal grid around the hybrid patent network linking science, patent law, and economy (Bowker 1992; Sherman 1994; Pottage 1998). Thus, at least in the context of patent law, technoscientific novelty becomes "possible to know and to say only within a taxonomic area of visibility" (Foucault [1966] 1990, 137), that is, against the background of patent classification.

An apt site for examining legal-scientific epistemic relations is the making of a new patent category in which the law had to respond to novel scientific developments. I study the creation of a patent category for combinatorial chemistry, which was incorporated into the IPC as the new subclass C40B in January 2006. The case study presented here is based on the working group files of the IPC revision group of the World Intellectual Property Organisation (WIPO) which was at work between 2000 and 2004. My guiding questions are: how are scientific and technological inventions identified and stabilized as a certain kind and ordered into a patent class? What kind of material and representational practices underlie the classification exercise? Who are the actors in the legal knowledge-making process and in what kind of institutional structure do they operate? Exploring the representation and classification of scientific novelty in patent law, this paper offers a contribution to social and historical studies of patents as science-law hybrids, with insights into the complex interaction between legal doctrines, forms of representation, and material practices of patent law which result in an order of technoscientific objects at an unexpected place.

The article begins by considering the significance of patent classification. It describes its use in searching the state of art by patent examiners and its role as a source of information for patent users. It then analyzes how patent classification forms an epistemic grid by which documents, spaces, and actors are organized in patent bureaucracy. Particular attention is paid to its historical development, which is essential for understanding the ways in which classifying practice shapes and, in turn has been shaped by, the materiality of patent administration. The second part of the article examines the creation of a new patent category for combinatorial chemistry. After a brief description of the technology in question, it presents case study material, the actors, and the processes of the working group. The core analysis consists of a discussion of the areas of substantive disagreement. I argue that these were solved with administrative and practical concerns in mind. The central part of the article describes and analyzes how the definition and structure of the patent class were drafted with primary concern for the material management of patent documents, although the classifying officers also saw themselves as being engaged in the classification of the very scientific and technological subject matters described and claimed in the patent documents. The article concludes by discussing the implications of these findings in the broader context of science and the socio-legal studies of patents. In particular, it raises questions about the common characterization of patents as hybrids between scientific and legal practices. The analysis suggests that the proportion of hybridity 
varies considerably at different points of the patenting process. At the point of patent classification, the invention as inscribed in the patent document is transformed and stabilized into a legal epistemic and administrative category for patent bureaucracy. I begin by providing some contextual background to explain the patent classification practice and its significance.

\section{Why does patent classification matter?}

"Classification is a key tool in the patent granting process," states a recent conference report on the development of a common classification system between the European and the US patent offices (EPO and USPTO 2011, 11). For patent users, "classification of patent domain ... is key information for searching patents across nations" (Bonino et al. 2010, 31). Although patent classifications draw epistemic demarcations that have significant implications for technoscientific practice and related commercial strategy (Parry 2004; EPO 2012), there has been no detailed analysis of patent classifications and their social effects beyond discussion by patent information professionals regarding their practical uses. This may well be a sign of their scholarly invisibility, but does not necessarily imply insignificance. Star and Bowker described classifications as relatively invisible blackboxes of varying degrees of openness, which nonetheless have considerable political and ethical implications (Star and Bowker 1999). In light of the lack of discussion of patent classification from a social science and historical points of view, I hope that the following analysis will offer compelling reasons for further study of patent bureaucracy and classification in actual practice. As this article focuses mainly on the transformation of scientific invention in the making of a new patent class, it cannot offer a thick and rich description of classification in action, even though that would be a fascinating study.

The effects of patenting on scientific practice and related commercial strategies have been well documented and contested (Thackray 1998; Rai 1999; Lenoir and Giannella 2006). It is worth examining how exactly scientific knowledge travels, is received, transformed, and administered in patent law. The patent classification system is an overlooked blackbox which deserves more attention than it has so far received and ought to be examined closely for at least two reasons: first, for its role as a source and grid of knowledge about inventions and their fields, and second, as an epistemological and practical framework underlying patent bureaucracy. As I will argue below, patent classification informs the organization of patent information and bureaucracy, and thereby also the application of patent law.

\section{Mapping, searching, and retrieving legal and scientific information}

Analyzing patent classification allows insights into the relationship between science and patent law as it is the epistemological framework by which scientific knowledge 
becomes ordered and administered in patent law. Patent classification aims to provide an accurate and comprehensive system for the storage, order, search, and retrieval of information about patented inventions and other relevant non-patent material, both for patent examiners and other patent users. There are two aspects to its informative function: it serves as a tool to organize and search for state-of-art innovations in the patent application process, and as a source of information about a scientific or technological field and its commercialization.

i) Use of patent classification as a tool to organize and search patent information: Patent classifications have primarily been designed for and maintained by patent examiners as tools for searching the existing state of the art and for organizing their work (van Dulken 1998). According to patent law doctrine, inventions must be novel and nonobvious in relation to already existing inventions in their field, called "prior art" in legal parlance, in order to be patentable. The search constitutes a central step in the patent application process in which the patent examiner looks for such prior art, which comprises relevant past patented or patent-pending inventions in the field of the invention, as well as other already published material.

One of the first steps in the patent examining process is the identification of the subject matter of the invention and the corresponding patent class for prior art search. At the EPO, a patent application is ideally assigned an official classification before a search is carried out and the application is published. ${ }^{1}$ One may wonder whether classification is just an internal system of filing which examiners have set up or whether it is indeed used as a practical search tool. In fact, the effectiveness of both functions are dependent on each other because it is in the self-interest of the examiner to file correctly in order retrieve relevant information for re-use in future patent examinations (Rampelmann 1999). Whilst the first point is not insignificant in itself allowing insight into what happens to a patent application once it has been "filed," a point to which I will return later, classification search constitutes an essential search technique. Without wishing to become overly entangled in an extensive discussion about how search is done, ${ }^{2}$ it is important to point out that the identification of the correct patent class for search is regarded as essential as it is "the only way for us to find the publications and papers we need among all the millions of documents available to us," as a European patent examiner expressed it (EPO 2011, 11). The patent examiners have an incentive to classify well as they are also the main users of the classification. A careful and consistent classification of patent documents and other relevant literature is seen to be a "real labor-saving incentive" (Wolter 2012, 9).

\footnotetext{
${ }^{1}$ The class can also be altered after a search if the search results indicate significant deviation from its original classification (EPO Guidelines 2010 Part B Ch. V Sect. 4).

${ }^{2}$ For an introduction to patent searching, see van Dulken 1998; for a more comprehensive overview of different search techniques and databases, see Adams 2006; on the specificities of IPC search post-2006, see Cullen 2009 and Wolter 2012.
} 
There are detailed and lengthy instructions about the hierarchy and techniques of prior art search in major patent offices. ${ }^{3}$ According to the US MPEP, classification search and a limited classification search are two of the search techniques most commonly used by patent examiners. In Europe, the EPO Guidelines recommend selecting multiple classes for search when conducting classification search. ${ }^{4}$ There are many different patent classification systems, such as the more detailed US patent classification (USPC) and European patent classification (ECLA). Both systems will be merged into a single Cooperative Patent Classification (CPC) based on the IPC, which will be launched in January 2013. At present, the only way to conduct an international search of multiple language patent documents is via the IPC. Particularly with the introduction of the substantially reformed eighth version of the IPC (IPC-8) in 2006, it has been argued that classification search has vastly improved in accuracy and relevance (Wolter 2012; for detailed effects on search practice, see Cullen 2009). The IPC-8 entailed the reclassification of all previous patent documents into a single scheme, a mammoth effort that is still continuing. Moreover, it introduced the principle that all members of a patent family (a group of patent documents which concern the same invention and share the first date of application, "priority") are assigned the same classification symbol as its original patent document. The IPC has also incorporated many of the detailed categories of ECLA and can be searched in varying degrees of detail via the ECLA (Albrecht et al. 2010). These changes have significantly improved the IPC in the last five years so that it has become, in the words of a patent information professional, "more flexible and rather quick to respond to changes" (Wolter 2012, 9).

At the same time, together with the significant improvement of the IPC in the last five years, the trend in patent searching has leaned towards keyword search with so-called full-text "intelligent" semantic search software, a development which can be observed by the frequency of these issues discussed in World Patent Information, a journal devoted to patent information. It has been noted, however, that such automated keyword searches of patent information do not take into account that patent documents are "usually longer than ordinary papers, with significant length variance; they adopt different writing styles in different parts; they often include multimedia data, typically drawings or mathematical or chemical formulas, which require specific analysis and classification algorithms" (Bonino et al. 2010, 31). In other words, such search techniques may "grossly underestimate the ingenuity of human (and lawyer's) minds in formulating patent applications" (Wolters 2012, 8). The drafting, reading, and interpretation of the latter require expertise and training (Myers 1995). Semantic

\footnotetext{
${ }^{3}$ United States Patent and Trademark Office's (USPTO) Manual of Patent Examining Procedure (MPEP) Chapter 900, Version 2010, and EPO's Guidelines for Examination (EPO 2010, Part B). In the US, when performing the first search for prior art during an examination, the patent examiner is required to fill out a search-notes form, which specifies in detail the different ways in which a search can be conducted (MPEP, $\S 719.05)$.

${ }^{4}$ EPO Guidelines 2010, Part B, chap. 6, Section 2.2.
} 
search outcomes do not always accurately reflect the nature of the patented invention (Cullen 2009).

The role of patent classification is to provide a systematic and definitive organization of patent information as it is perceived and already differentiated by patent officers. A recent decision by the EPO reflects this premise. The new Cooperative Patent Classification will convert common keyword searches employed at the EPO into separate classification groups (Swedish Patent and Registration Office 2011). Keyword searches are to be incorporated and subsumed into the overall classification rather than the other way around.

An IPC-based classification search is by no means an exclusive or primary strategy of search, especially with the advance of web-based patent databases (e.g., Google patents, encompassing US patents), as well as established proprietary patent databases which are much used by professional patent searchers. Commercial patent databases also always include the IPC symbols, even if it has its own proprietary classification system, such as the Derwent Manual Code (Van Thielen 1998). Depending on the subject, different non-legal classifications and databases are used for search, such as the Chemical Abstracts Services Registry of the International Chemical Union or the bioinformatic databases of EMBL-EBI (European Molecular Biology Laboratory maintained by the European Bioinformatics Institute). However, even in these subject areas, IPC searches are conducted in conjunction with keyword or sequence searches in order to ensure that one has not missed any relevant patent information (Dirnberger 2011, 140).

It is also worth noting that, although the flow of information between the patent classification information and the various databases is mutual and non-exclusive, there is a hierarchy of database information. The ultimate validity of patent information remains with the patent offices and their own databases, all of which are assigned an IPC symbol. For example, the nucleotide sequence database of the EMBL-EBI receives sequence data published in patent documents from the EPO by automatic procedure (Baker et al. 2000) and treats patents as an internal data class ("PAT"). In turn, the EMBL-EBI is also used for search by the EPO examiners. All inventions containing patent nucleotide sequences are classified according to the IPC. In case of discrepancy, the identification and representation of a nucleotide sequence in the patent document overrides its identity in the EMBL database (EMBL Release Note 1998).

In sum, despite the multiplication of different databases as tools for search and different search techniques, patent classifications, and especially the IPC, remain the most authoritative and universal tools for patent examiners to identify, organize, search, and retrieve patent information. The decision to build up a joint classification system between the European and the US patent offices based on the IPC attests to the vital importance of IPC for international search and retrieval and thus for the functioning of the increasingly internationalized patent administration (EPO \& USPTO 2011). I will discuss the international use of the IPC later in more detail. 
ii) Patent classification as an indicator of scientific activity and as a source of scientific information: A well-functioning patent classification system is vital to the functioning or at least as Mirowski would argue, to the maintenance of the illusion - of the patent agreement which legitimizes the granting of patents as limited monopolies in exchange for making accurate information about patented inventions freely available. ${ }^{5}$ The digitized and freely available IPC acts as a gateway by which inventors and other interested parties can hope to find and retrieve relevant inventions of a similar kind clustered together, helping them to focus and refine the search (van Dulken 1998, 83).

For patent users, searching for and identifying relevant patent information is of central importance when considering whether to file for a patent or to sue for infringement of one's own patent. A search can thus serve different purposes (Adams 2006): to ensure that there are no other similar inventions that have already been patented or have applied for a patent (novelty search), to ascertain that an invention does not infringe any existing patent rights (infringement search), or to find out whether an issued patent is indeed valid (validity search). Search strategies and degree of detail will differ depending on aims, budgets, and timeframes. ${ }^{6}$ Expert searchers conduct classification searches in conjunction with other search techniques, such as keyword search, in order to ensure that they have not missed out on any important prior art:

At their most fundamental, these experiences (from other searches) promote the idea that word-based searching will serve to retrieve sufficient numbers of documents, sufficiently precisely, to fulfil the information need. Unfortunately, in patent searching, the legal requirements do not allow this flexibility. To ensure that a greater proportion of the prior art is found, the great majority of searchers will eventually move to supplement their word searching by other means, which often includes classification. (Adams 2006, 195)

Rendering effective search results presupposes more than just the correct identification of a class. It requires a good understanding into the history and hierarchical structure of a classification, making it essential "to consult the full IPC schedules, to look at the hierarchical context in which the code exists, to read the notes, to consider searching using a less specific code and to consider alternative codes" (van Dulken 1998, 86).

Beyond its use as a tool for search, patent classification is increasingly viewed as a data mining tool to fathom scientific and technological developments: "analysing patent classifications ... can help to identify changing combinations of existing technology and to spot new technological trends" (EPO 2012, 6). Patent classification categorizes specific technologies rather than whole commercial sectors (Schmoch 2008). Arguably it may be more reflective of the level of commercialization of specific technologies rather than their actual practices (Dubaric et al. 2011). Such a conflation of patent

\footnotetext{
${ }^{5} \mathrm{I}$ am grateful to Bengt Jonsson for raising this point of the role of patent classification in relation to public interest to me (email correspondence, 22 November 2010).

${ }^{6}$ Personal correspondence with patent lawyer, Jae Park at Venner Shipley (interview, 23 March 2012).
} 
categories with technological fields can be found in a study into the value of patent which employs IPC classes in order to measure the "level of inventiveness" (PatVal-EU Project 2005, 18).

Related to these uses of classification as a technology indicator, patent databases are perceived as important sources of scientific and technological information. According to a European survey, inventors who already hold patents regard patent literature as a slightly more important source of knowledge than scientific literature (ibid., 30). ${ }^{7}$ Also noteworthy - going beyond immediate patenting considerations - is the following observation by bioinformatic researchers of the EBI and EPO officers in a joint article: "searching patent sequence databases can be used as inspiration for scientific innovation and discovery of existing inventions (e.g. industrial processes) with relevance to the work of the researcher," particularly since "information in patent data can be more detailed, appears earlier or is not available in scientific literature" (Li et al. 2010). In light of the tenfold increase of publication of biological sequences appearing in patent documents over the last ten years, ${ }^{8}$ patent databases already represent non-negligible sources of bioinformatic data. The results of a nucleotide sequence search are refined by an IPC search and identification of the patent family in order to avoid duplicate entities (ibid.). In other words, a legal classification is employed as a tool to extract scientific data. And as mentioned before, the validity of the sequence data rests with the patent office, not the EBI.

Extending the scope of application to other documents beyond patent documents, the EPO has increasingly categorized non-patent literature, such as journal articles and conference proceedings, into patent classes (EPO 1998). This may be understood as a further extension of the knottings between the scientific, legal, and commercial knowledge domains and ways of knowing. Such an expansion of the logic of patent classification beyond patent documents, however, raises questions about what exactly it is that patent classifications classify and how it is done. As this article will argue in detail in the later case study, extending the application of patent classification is by no means straightforward because it is based on the specific material needs of patent administration and its representational practice rather than reflecting an archive of past scientific things.

\section{Organizing patent bureaucracy}

The second relevance of patent classification to the study of the relation between science and patent law consists in the role of patent classification in patent administration. An

\footnotetext{
${ }^{7}$ Patent literature 58.87 per cent and scientific literature 58.79 per cent.

${ }^{8}$ There were approximately two million entries in 2004, which increased to over twenty million by 2012 , measured by the number of entries in EBI's patent database reflecting US and European patent data (EMBL Release Note 2012).
} 
analysis of patent classification brings to light the materiality of patent law bureaucracy, an aspect which has largely been overlooked in the historical, social, and legal analyses of patents. Scholars from various disciplines have already provided insightful analyses of the materiality of physical, written, and visual representations of inventions in law (Myers 1995; Biagioli 2006; Rankin 2006; Pottage and Sherman 2010). If the textual inscription of the invention in patent law "both fostered and needed to be managed by a bureaucracy like that of the patent office" (Biagioli 2006, 1160), it is patent classification that links the organization of an invention's legal-textual embodiment to patent law bureaucracy. The patent classification is not only a legal epistemic order and archive of patented inventions; it also maps the trajectory and location of patent documents, and thus acts as a framework that holds together the material practice of patent administration with the legal substantive activity of assessing patentability (see Desrosières 1990 for the reciprocal effects between epistemological status and administration). The answer to the question of "how are patent documents managed in bureaucracy?" would be, to a considerable part, "by their classification."

The reciprocal relation between patent classification and the organization of patent administration could not be stated more clearly than in the EPO's Implementing Regulations, the document which outlines how the European Patent Convention ought to be put into practice:

The President of the European Patent Office shall determine the number of Search Divisions, Examining Divisions and Opposition Divisions. He shall allocate duties to these departments by reference to the international classification [IPC] and shall decide where necessary on the classification of a European patent application or a European patent in accordance with that classification. (EPO 1973, amended 2001, chap. 2)

The EPO's administrative organization does not only reflect the IPC, but it also uses the IPC as a tool for routing patent applications within the office. The organization of patent examination is co-constitutive with channelling the classification "workflow" as described in the following passage by the EPO's Patent Information Resource division. It is remarkable in that it reveals the fluid co-constitution of the European with International patent classifications and the process of patent examination and is worth recounting in full:

the first patent family member arrives in the simple patent family and triggers a distribution process to the classifier community. The classifier community consists of experts in well over 2000 technical fields corresponding to sub-ranges of the ECLA scheme. Specialised examiner-classifiers are assigned to one or more of these ranges.... correspondence tables between the IPC and ECLA ranges have been established. With this set-up in this distribution process, the documents to be classified find their way to the responsible classifier by means of the IPC symbols allocated by the patent-issuing authority. On opening his or her classification in-box the classifier can choose to allocate classification symbols or forward the document to colleagues in any technical field, to 
share information of potential mutual interest.... After classification, all the documents of the simple patent family can be retrieved in the EPO search database with a classification search. (Albrecht et al., 2010, 284)

Thus, classifying and ordering patent documents simultaneously constitutes an administrative molding of a pathway around which future inventions and patent applications are channeled and assessed. In the life of a patent application file, it is first "preclassified" upon submission in order to determine its "route" within the Search Division. The relevant section in the EPO Guidelines is aptly titled "Preclassification (routing)." At a later stage, the patent application will normally be allocated to an examiner according to its IPC identification made at the search stage. ${ }^{10}$ Similarly, current arrangement in the US Patent and Trademark Office (USPTO) reflects how classification serves as the underlying infrastructure of patent administration. The initial work of classifying a patent application is carried out by the Office of Initial Patent Examination, which passes the application on to the relevant art unit in a Technology Center responsible for that USPC class or subclass. ${ }^{11}$ A supervisory patent examiner then gives the application a primary classification and assigns it an examiner for examination (MPEP $\$ 903.08$ [a]). According to patent practitioners, the classification and the corresponding assignment to an art unit determine the length of time and the chances of success of obtaining a patent (Quinn 2012), which also implies that "selective targeting" of a patent class can influence the prospect of success or rejection of an application (Nowotarski et al. 2011). ${ }^{12}$ Thus classification not only identifies the nature of invention, but furthermore acts as a practical route by which patent documents travel through the examining process and are assigned individual examiners. It allows "a glimpse of the examiner's desk and also into her or his reasoning" (Wolter 2012, 17). It is in this sense that the patent classification exerts another kind of "real world" consequence, not only by mapping the prior art search, but also by organizing patent bureaucracy.

The role of classification as an organizational grid is closely coupled to the way in which patent administration and representational practices have evolved over time.

\footnotetext{
9 "In order for an application to be allotted to the competent directorate, a preclassification must be made. The level of classification at this stage should be as general as practicable on the basis of a quick and cursory scrutiny of the document (e.g. the title and independent claim or claims). On the other hand, the level should be specific enough to avoid the need for any intermediate stage of preclassification before allocation to the competent directorate" (EPO Guidelines 2010, Part B, chap. 5, Sect. 2).

${ }^{10}$ Usually the search and substantive examination is conducted by a single examiner. There may be instances when the application is passed to examiners who are not "normally responsible for the indicated part of the IPC” (EPO Guidelines 2010, Part C, chap. 6, 1.2. "Allocation of the application”).

${ }^{11} \mathrm{See}$ http://www.uspto.gov/patents/resources/classification/art/index.jsp for the assignment of USPC subclasses to technology centers. For the internal organization of technology centers broken up into art units, see http://www.uspto.gov/web/patents/contacts/tcmgrs.htm\#1600nav (last accessed February 28, 2012).

12 The database Patentcore allows a statistical analysis of patent granting and refusal rates by identification of an art unit and their individual examiners, as well as the legal basis of their decision, <www.patentcore.com $>$.
} 
Understanding how classification has evolved is thus crucial for interpreting the IPC practice today. The following discussion aims to show how patent classification has been shaped as a response to material necessities of patent administration, which in turn was propelled by historical changes in the mandated form of representation and legal patentability requirements.

\section{Historical formation of patent classification}

The development of patent classification is closely related to changes in the way inventions were represented in patent law, the accompanying legal doctrinal changes, and the resulting organizational needs. Here I will provide a brief presentation and discussion of patent law's representative practice only as far as it pertains to the development of patent classification.

During the late eighteenth century, the patent changed from being a privilege - a discretionary monopoly right over the use of an inventive thing or method granted by the monarch - to being a right, in an inventive idea specified in writing in a document. This complex historical shift, which occurred between approximately 1790 to the mid-nineteenth century, has been analyzed in great detail elsewhere (MacLeod 1988; Sherman and Bently 1999; Bracha 2005; from a perspective of history of sciences and law, see Biagioli 2006 and Pottage and Sherman 2010). Central to this change was the requirement that inventions had to be described in writing. Writing down what the invention was about was not only in the interest of the inventor in order to claim his right in case of violation, as had been practiced before 1790 (MacLeod 1988, 53); but the 1790 US Patent Act also marks the critical moment at which a patent for an invention would be granted only if it had been sufficiently described in writing so to enable a person in a similar technological field to reconstruct it (Bracha 2005, 431; Biagioli 2006, 1135). ${ }^{13}$ Behind it was the idea of a quid-pro-quo patent agreement: only in return for a written, "enabling" disclosure, would the inventor be granted a temporally limited monopoly right. The textual inscription of the invention led to the gradual articulation of the invention as an "inventive idea" rather than the actual material thing itself. Pottage and Sherman argue that it was especially the introduction of patent reissue in 1832, allowing the patentee to rewrite an issued patent and get it reissued, which established the primacy of written inscription as the primary embodiment of the inventive idea aside from the use of patent models as inventive embodiments (Pottage and Sherman 2010, 109-125). ${ }^{14}$

\footnotetext{
${ }^{13}$ In legal wording, this requirement is called "constructive" "reduction to practice" (USPTO 2008, MPEP, $\S 2138.05)$ or in Biagioli's description, "virtual” reduction to practice (Biagioli 2006, 1139). Written descriptions of inventions existed as early as 1594, of Galileo's water pump, but did not have to be detailed enough to enable another person to reconstruct it (ibid., 1132).

${ }^{14}$ Notable exceptions and hybrid modifications to the requirement of textual and visual representation are plant patents (Pottage and Sherman 2007) and inventions involving biological materials (Parry 2004). In the
} 
The 1836 US Patent Act introduced three aspects central to the development of patent classification: the establishment of the US Patent and Trademark Office; the requirement that applicants include claims (the inventive idea which the applicant defines as her own) in addition to the detailed description; and the accompanying changes in interpretation of an invention's novelty in relation to prior art. Biagioli argues that prior art came to be defined as the range of texts available to the examiners, excluding physical machines and working models, so that novelty of an invention was ascertained by "checking text against text" (Biagioli 2006, 1152). Thus the novelty of an invention was instituted by the legal written records of past novelties, the determination of which, in turn, would form one of the bases of a future patent right. ${ }^{15}$ More specifically, the 1836 Act introduced the idea of claims as the boundaries of a patent right. Claims thus started forming the central link between the patent document and the patent right of an invention. ${ }^{16}$ Taking Biagioli's observation of fundamentally different nature of description and claims a step further (ibid., 1135), I would suggest that such an understanding of claims reveals that it is not the actual invention which is represented in a patent document, but rather a purely legal semantic reconstruction of it. This is because claims are inherently semantic and interpretive demands (frequently formulated as "what is claimed is ...") in contrast to descriptions which aim to represent something else ("the subject invention concerns ..."). Revealingly, modern patent law does not assume identity between the claims and the written description, only requiring a degree of "conformity" (USPTO MPEP 2010, 608.01 (i)(d)). I would thus argue that the central status of claims in modern patent law transformed inventions into fully virtual legal reconstructions rather than representations. Therefore, at the level of patent law practice, it is not surprising that the issues of representation and materiality have become rather secondary to the questions of how to write, read, and organize the body of claims and its textual setting. ${ }^{17}$

latter context, for example, a physical sample of lower life forms has to be deposited in any one of the designated depository agencies agreed on in the 1977 Budapest Treaty on the International Recognition of the Deposit of Microorganisms for the Purposes of Patent Procedure. As Pila writes, the problem of representation and written description concerned all inventions involving biological material, and thus were not new to biotechnological inventions (Pila 2003, n. 28), and it was resolved in the US, for example, prior to an express confirmation of patentability of biotechnological inventions by recognizing the deposit of a micro-organism as sufficient for disclosure for patent law purpose (see In re Argoudelis, 168 U.S.P.Q. [BNA] 99 [C.C.P.A. 1970]).

15 The phenomenology of modern patent law doctrines operates in past, present, and future perfect modes: an invention always has been novel and will have been useful (Kang 2006). With the 1836 Act, whereas the written specifications made novelty materially graspable, the ill-defined requirement of utility of an invention became further displaced into an "emergent" future (Biagioli 2006, 1155).

${ }^{16}$ Brennan observes in the English patent law context that the separate and divergent aims of describing and claiming the inventions crystallized in the first part of the nineteenth century. Descriptions would disclose the whole invention, whereas the claims would point to its novel aspects. It is important to distinguish between the practices and interpretation of claims by patent office and the courts. As Brennan describes, claims would not start to fully function as principal property definers until the case of Seed v Higgins in 1852 (Brennan 2005).

17 This observation does not apply to patents granted on plants and biological material, as detailed in footnote 14. 
Although the specific materiality of written specification led to substantive changes in legal practice and doctrine, especially between 1790 to 1836 (Biagioli 2006, 1160), what is not entirely clear is the detailed degree by which the former propelled the latter. Then and now, the technique of drafting, forming, and interpreting patent documents has rested on an essentially mechanical understanding of inventions (Bracha 2005, 442-448; Pottage and Sherman 2010, 65-106). Patent documents have been understood as textual machines, the inventive essence of which could be discerned by the interpretation of description and of the claims, in particular. However, interpreting claims is complex and bound to legal semantic constructions (Burk and Lemley 2005). Documents do not communicate by themselves - they have to be prepared for legal communication by reading and interpreting what inventive ideas they embody. Inscriptions and forms have to be streamlined and organized in order to differentiate them from preceding ones. This means that the material act of their organization and filing is simultaneously an interpretive and constitutive act. And this is where the patent classification comes into the picture.

Derrida had once observed that an invention is identified by its ability to be repeated, exploited, and reinscribed (Derrida [1987] 2007, 6). And such ability could only be provided by the management of patent documents, which became vital for the functioning of the patent system as a whole: "the usefulness and efficiency of our patent system are in a great measure dependent upon a proper and careful classification of issued patent" (Rossmann 1933, 3). The physical documents facilitated the examination procedure by virtue of their relative ease of storage, retrieval, movement, and organization (Vismann [2001] 2008; Riles 2006). But they needed to be routed, streamlined, preserved, and filed for search and retrieval. The notion of patent documents as material embodiments of inventions meant that a disorder of patent documents would amount to a loss of past inventions, which would make the assessment of novelty and inventive step of present and future inventions impossible. As "patent systems ... were predicated solely upon internal networks of textual referents" (Mirowski 2011, 191), the organization of patent documents was crucial to the very functioning of the patent system. Patent classification therefore originated from the needs of a specific legal representative practice in which inventions, or rather inventive ideas, have come to be equivalent or even identical to the written claims in patent documents.

Many alphabetically ordered lists resembling some sort of classification were established in the nineteenth century. ${ }^{18}$ However, these early patent classifications were unhelpful as they were in alphabetical order instead of being ordered by content (USPTO 2005). In an effort to introduce an effective classification system, the United States Congress authorized the establishment of a separate classification division within

\footnotetext{
${ }^{18}$ France made an alphabetical list of granted patents in 1791 (WIPO 1995, paras. 25). Generally, classification systems were introduced as early as 1831 at the USPTO, 1877 at the German Patent Office, and 1880 UK PTO, but they were not necessarily grouped thematically (WIPO 1997, 107).
} 
the USPTO in 1898. The high volume of patent applications filed and issued between 1870 and 1933 (Rankin 2006, 4) made the classification of prior art pressing, since "a thorough and complete patent search cannot be made either by the Patent Office corps or by the public without a dependable and working classification of patents kept thoroughly up to date" (Rossmann 1933, 3). By 1934, the USPTO faced "a huge tangle of mass of patents, poorly classified, scattered unsystematically in numerous unrevised and obsolete classes, and no sufficiently detailed index to facilitate the location of all the pertinent patents," which "has grown to such large proportions, owing to the great flood of issued patents, that it seriously hampers the normal functions of the Office" (ibid., 4).

The formation of patent classification expertise was characterized by a blurred boundary between the classifying and examining expertise which was reflected in the fluid spatial organization at the patent office. The examining officers sat together with the classifying officer in the same room organized by subject areas from 1917 (Kinnan 1920; Rossmann 1933). In this constellation, this classification "sort of team" (Kinnan 1920, 336) represented a curious hybrid mixture of administrative, legal, and scientific identities: a patent examiner, who himself was a hybrid actor between science and law (Swanson 2009), was also at the same time the classification officer with the task of managing and administering the patent documents. ${ }^{19}$ Classification expertise was seen as co-evolving with the patent examining practice on the ground and was placed at the service of the latter's needs. In this constellation, the act of classifying coincided with the legal interpretation of what constituted the inventive idea in the patent text. Classification thus represented the body of the legal reception of inventive ideas, rather than an order of the inventive ideas themselves.

The attempt to demarcate inventive knowledge went hand in hand with spatial attempts to organize patent documents in folders, drawers, cabinets, and rooms. The historical debate about classification conducted in the Journal of the Patent Office Society, the house journal of the USPTO, in the 1920s highlights the close link between patent administration reform and the modernization of its storage and filing practices. Although in comparison to machines, models, and samples which had to be previously deposited at the patent offices, documents needed significantly less physical space (te Heesen 2000; Riardan 2002; on contemporary biological sample deposit, see Parry 2004), space was still a scarce resource. The chief clerk and editor-in-chief of the Journal, William Wyman, documents the paper chaos inside the Patent Office:

\footnotetext{
${ }^{19}$ This constellation relying on a combination of examining and classifying expertise still applies to major patent offices, for example the EPO or USPTO, however with varying degrees of control of the quality of the classification made and resources devoted to specific classification expertise. The USPTO Office of Classification has been reduced to one person, as of January 2012 (Wolter 2012). The EPO has an additional patent information resource department which is entrusted with the maintenance and reclassification efforts of all patent document files of the IPC ("Master Database") in addition to doing the same for its own in-house databases, such as ECLA and non-patent literature classification.
} 
The demand for filing space to store the permanent records of the Office and copies of patents, trademarks and designs for sale, is prodigious and almost insatiable. Every year 4000 running feet of shelf room must be built for the storage of copies of patents, trademarks, etc., 1500 running feet erected for the files of applications finally disposed of, and over 1200 linear feet of shelving and drawer space must be provided to contain copies of patents, etc., for search purposes. (Wyman 1922, 60-1)

Considerable effort went into the material standardization and organization of paper in folders, cabinets, and rooms. Indeed, as the act of filing became synonymous with the very act of applying for a patent application - in legal parlance, one "files" for a patent - the mundane process by which patent documents were filed and organized became highly specified, underlying fastidiously detailed material requirements. ${ }^{20}$

The organization of paper simultaneously mapped out an administrative and spatial order: "A regrouping [of patent documents] was planned, whereby 10 sections were organized ... and each forming a self-contained, complete administrative unit" and, as such, it was an essentially physical act of reorganization: "The plan ... required the transfer, inspection and restoration of about 1,500,000 bundles, thus constituting what is undoubtedly the largest physical performance ever undertaken in the Patent Office" (ibid., 62). Classification was a physical arrangement which had to be conducive to "simplicity of manipulation in use": "the broad definition of classification . . . covers not only the arranging in order of knowledges as embodied in paper prints and writings and preparing indexes for the same, but also the sorting and arranging as to their relative physical positions of all manner of other material objects" (Swanton 1922, 469; emphasis added). Knowledge was compartmentalized by being stored in different rooms, which are until today called "search rooms" that are organized according to classification numbers and their corresponding art units. ${ }^{21}$ The ability to arrange patents into classes was thus closely related to the ability to manage files within given spatial and physical restraints. Whereas inventions had become more temporal and less bound to geography after 1790, as Biagioli (2006) argued, it seems to me that their legal written reconstructions had to be assigned specific spaces again for the purpose of patent bureaucracy (Biagioli 2006).

\section{The Internationalization of Patent Administration and Information}

The organization of patent documents became even more pressing with increasing interrelations between different national patent systems requiring international coordination. This is still an ongoing concern, however, with significantly different material possibilities in light of the digital conversion and online availability of much of

\footnotetext{
${ }^{20}$ Today at the USPTO, all documents relating to a patent application are put in folders, called "file wrappers," and now predominantly digital "virtual image file wrappers." The MPEP instructs in minute detail how the papers inside wrappers should be organized (§719.01).

${ }^{21} \mathrm{http}: / /$ www.uspto.gov/patents/resources/classification/numeric/can.jsp (last accessed August 12, 2012).
} 
patent data, as will be shown later. Although patents still underlie national and regional jurisdictions after grant, the process of obtaining one, especially the process of search, depends on proving absolute, international novelty, which requires the organization and harmonization of international patent information for prior art search.

The 1883 Paris Convention for the Protection of Industrial Property facilitated the filing of patent applications in different jurisdiction by introducing a system of international priority which would grant applicants a breathing period of one year in which the novelty of an invention would be "frozen." Novelty had to be established only starting from the date of the original filing. This implied that prior art search would start from the year of first application in one of the member countries, even if further applications were submitted elsewhere. In 1970, the Patent Cooperation Treaty (PCT) established an international patent filing system by which one patent application could be filed for all states party to the PCT, thereby eliminating the need for filing separate national patents. In light of increasing PCT and cross-country filings, an overarching classification linking the different national and regional patent documents and their classifications was needed in order to facilitate patent examinations.

The International Patent Classification (IPC) was the response to the need to identify and access patent documents across jurisdictions. With the specific aim to facilitate international searches, the IPC was created by an international treaty, the Strasbourg Agreement of 24 March 1971. It was to provide "a uniform means for obtaining an internationally uniform classification of patent documents" (WIPO 2008, §6) which would complement and harmonize national and regional classifications and assist patent examiners and potential patent applicants in their international search. The distinctive characteristic of the IPC is that it is the only meta-level framework linking different national and regional patent classifications that would otherwise not be related to each other: "IPC is the only binding element among a (growing) plethora of unrelated and specialised tools" (Foglia 2008). It is almost universally used by all countries with a patent law system. In 2009, this came up to about one-hundred national patent offices, four regional ones and the WIPO bureau. ${ }^{22}$ Almost all published patent documents and applications are assigned with an International Classification symbol, either by direct IPC identification in addition to their own symbol or by linking their own patent classes to the IPC classes. ${ }^{23}$ An increasing number of patents are only published with an IPC symbol.

As the IPC is the only common denominator between national, regional, and proprietary classifications, it is the key tool for searching patents internationally,

\footnotetext{
22 http://www.wipo.int/classifications/ipc/en/general/preface.html (last accessed January 29, 2009).

23 The US Office of Patent Classification prepares and regularly updates a list of concordance between IPC and USPC, which represents a guide to be used "in conjunction with the IPC and not as a translation list" (MPEP, §903.09). The IPC symbol is placed in addition to the US patent class on the Image File Wrapper. The IPC identification is central for the convergence into the CPC which is based on the European patent classification, which in turn is based on IPC.
} 
especially in light of the rapid increase in the number of non-European patent documents (EPO 2009, 2). Its utility has significantly increased since the introduction of the reformed IPC (eighth version) in 2006 which has reclassified all patent documents into a single classification and linked them to the Master Classification Database, which is maintained by the EPO. Thus, a vast number of digitized patent documents can be accessed and retrieved through the electronic version of the IPC. Since June 2005, the internet publication of the IPC has been recognized as the official version and since 2010 the IPC has started being published only in electronic form (IPC Committee of Expert decision [IPC/CE/31] March 2009). The materiality of the patent documents and their classification thus is significantly different today than in the early days of classification: the digitization of patent information effects multiple and combinatory associations between electronic patent documents rather than a singular, spatial identity. Furthermore, the automatic organization of patent documents into patent families in the IPC (described earlier in the context of search) constructs a legal genealogy of patented inventions, which is completely independent of its geographical location. For instance, a patent document can belong to the same patent family even if it is also classified in Japanese File Index System, the IPC, and the USPC.

For conversion between national and regional classifications and the IPC, systems of concordance are in place, although they vary in accuracy. ${ }^{24}$ The Cooperative Patent Classification (CPC), the common classification of the European and US patent offices to be launched in January 2013, will be closely modeled on the IPC, adopting IPC rules and definitions. ${ }^{25}$ These harmonization efforts have strengthened the role of IPC in the international patent system rather than dispensing with it. The international IP5 initiative of the Chinese, European Japanese, South Korean and US patent offices, which started in 2008, has the aim of developing a common hybrid classification, the results of which are to be incorporated as new subdivisions into the IPC by 2021 . In an increasing overlap of workflow between international and national classifications, the IPC Committee of Experts has delegated the task of eventual revisions to the IPC

\footnotetext{
${ }^{24}$ Concordance to IPC seems to work worst in cases where classification is automated (as in the reclassification efforts of the PCT documents after the IPC-8) or inconsistent and incomplete classification in the national or regional classifications due to lack of expertise and/or resources (Wolter 2012, 15). The concordance between the IPC and ECLA is also not perfect, but the two are more closely interwoven. The EPO has spent considerable resources on the maintenance and updating of Master Classification database (MCD) containing all patent documents classified in IPC, a task which has been delegated to the EPO by the WIPO with the introduction of the IPC-8. The daily classification efforts of the EPO examiners feed into the maintenance and updating of the Master Classification Database by the use of the IPC symbol (Albrecht et al. 2010, 284).

${ }^{25}$ The US patent classes will be converted via its IPC identification into the CPC although it remains to be seen whether this automatic "conversion" will not contain too many inaccuracies to be sufficiently effective in the long run (Wolter 2012, 16). CPC will eliminate ECLA procedures incompatible with IPC classification philosophy and rules, and adopt IPC standards of data management (Swedish Patent and Registration Office 2011). ECLA classification titles will also be fully retitled into the IPC format (CPC Implementation Group $2011,8)$.
} 
to the IP5 offices since 2010, which is documented on the WIPO IPC e-forum web platform. $^{26}$

\section{Inventions that are "too novel": the making of combinatorial chemistry as a patentable kind}

If "classifications in the natural sciences are constantly being revised [as] it is the business of scientific research to modify existing knowledge, even as it relies upon it" (Barnes, Bloor, Henry 1996, 157), this observation equally applies to the IPC as its objects are inventions, which - by legal definition - need to be novel. ${ }^{27}$ The historical constitution of an invention's novelty is stated most clearly in the definition of the inventive subject matter as "the difference between the subject matter in a patent document and the collection of all technical subject matter that has already been placed within public knowledge" (WIPO 2008, §77-8).

The creation or expansion of patent classes represents the moment in which a type of invention is recognized as a "kind" deserving a separate classificatory location. However, such a creation of a brand new patent category has not been a routine practice even in the numerous revision cycles of the IPC. ${ }^{28}$ It can be understood as an ontological transformation of a scientific and technological novelty stabilized into a patentable kind within patent law's epistemological framework (Rheinberger 1997, 80-81). Simultaneously, as I had described in the first part of the article, it also represents a technique by which such a process becomes politically legitimized by forming a legal interpretive and bureaucratic chain of reference around it (Latour 1999, 63-70). Such a legal reception can occur quietly as in the case of combinatorial chemistry, or more visibly as in the case of change of patent classification system in the late 1970s and early 1980 s, which were propelled by advances in the field of recombinant DNA. ${ }^{29}$

\footnotetext{
${ }^{26}$ Available at: http://www.wipo.int/ipc-ief/en/. Category: F-Revision_IP5. For a complete list of past and current status of IP5 related revision projects, see http://www.wipo.int/ip5ef/ (last accessed August 12, 2012). ${ }^{27}$ Discoveries and natural substances are not patentable under the EPC (Art. 52 [2]). Different provisions exist under US law. However, the jurisprudence in this area is still by no means clear and remains contentious (see Relaxin 1995, Harvard Oncomouse 2002 Sup. Ct. of Canada decision differing from EPO jurisprudence [2003 Opposition Division], and Kirin Amgen [2002] RPC 187).

${ }^{28}$ Since its conception in 1971 to date, the IPC has undergone sixteen revision cycles. A major reform process was launched in 1999, the results of which were embodied in the version of IPC8, launched in January 2006. With the IPC harmonization effort (see footnote 25), responsibility for revision has been transferred to the five offices in 2010 (WIPO 2010, IPC/CE/42).

${ }^{29}$ In the context of recombinant DNA technology, a detailed examination of the timeline of legal developments indicates the close relation between the patent classification and the technoscientific current. Interestingly, patent classifications may have reflected the patentability of genetically engineered organisms prior to Diamond v. Chakrabarty (447 U.S. 303 [1980]) decision of the US Supreme Court, which held that a genetically modified micro-organism was patentable. The Chakrabarty patent document, filed on 7 June 1972, was assigned the IPC classification C12N 15/00 and the US class 435 with the title "Chemistry: Molecular Biology and Microbiology." The US patent class 435 was established in 1979, and the IPC subclass C12N was introduced in January 1980,
} 
Although all patented inventions become stabilized through their classification, the degree of their stability varies and is subject to constant revisions by reclassification. In the following sections, I present the case study of the making of a new patent category for combinatorial chemistry between 2000 and 2004 by a special subgroup appointed by the IPC Revision Group. The subject matter of combinatorial chemistry is certainly not unique in that the scientific object undergoes an epistemological and ontological transformation as any other such object would within the patent law system. Nonetheless, what made this particular scientific field particularly interesting to observe was its inherently "combinatory" subject matter, of which the core and other elements could not be easily agreed on and propelled substantive and structural disagreements in the classificatory process. The classification working group activity, moreover, coincided with a period of substantial transition in the IPC's role and materiality into an electronic framework of patent database by the eighth version of the IPC in 2006. Complex revisions to classificatory rules were introduced, such as multipleaspect classification and indexes, as well as the distinction between obligatory or nonobligatory classification depending on the subject matter's level of "inventiveness." 30 In the discussion of the classification process for combinatorial chemistry, I particularly trace the way in which the classification was shaped by considerations of these material and interpretive changes in the IPC practice.

Before I turn to the case study, a brief overview of the development of combinatorial chemistry is in order.

\section{A Brief Overview of Combinatorial Chemistry}

Combinatorial chemistry involves the practice of screening and synthesizing biological or chemical molecules in libraries or arrays on a large automated scale in order to search for useful properties intended for pharmaceutical or chemical material discovery processes (Czarnik 1999, 1). ${ }^{31}$ Different biological and chemical probes are gathered into a collection, which is then exposed to light beams or synthesized with other molecular probes, and is subsequently screened and analyzed for its structure. Traditionally, chemical compounds had been targeted and analyzed sequentially one

both prior to the US Supreme Court decision on 16 June 1980 and the granting of the patent on 31 March 1981. As Eisenberg (2006) writes, the patenting of DNA strands and purified compounds hardly drew any attention in the late 1970s and 1980s. Therefore it is not surprising to see that the patent classifications for these entities already existed prior to the much discussed Chakrabarty case.

${ }^{30}$ On these classification rules, see WIPO (2006) Guide to the IPC, $8^{\text {th }}$ version. In 2003, the Committee of Experts decided to divide the IPC into "obligatory" subject matter classes as opposed to "non-obligatory" ones. The former would determine the inventive nature of a subject matter class, whereas the latter classification is not sufficient by itself and can only be used in conjunction with the former if it helps carry out a search (IPC/CE/32/12).

${ }^{31}$ For a general introduction, see Combinatorial Chemistry Review: http://www.combichemistry.com/ index.html (last accessed August 12, 2012). 
by one, which was a slow and costly process. The novelty and utility of combinatorial chemistry consists in the amplification of scale and the acceleration of synthesizing processes, thus promising significant reduction in time, labor, and cost (Terrett 1998, 5).

The beginnings of combinatorial chemistry can be traced back to the 1960 s when Bruce Merrifield, who was awarded the Nobel Prize for chemistry in 1984, succeeded in synthesizing peptides in solid-state form in 1963. He used automated synthesizers and produced polypeptide chains of varying lengths, from amino acids to proteins (Merrifield 1963). The synthesizing method reached an industrial scale when Mario Geysen of the University of Melbourne succeeded in synthesizing a collection of multiple peptides in 1984. Geysen's method involved combining multiple amino acids with peptides supported on pins and thereby generating a whole library of synthesized compounds. ${ }^{32}$ This represented "a new concept . . by which a collection of molecules is targeted, simultaneously producing a library of compounds instead of a single product" (Nicolaou, Hanko, Hartwig 2002, 3). The early-to-mid-1990s witnessed an exponential growth in related publications in this field, and combinatorial chemistry became demarcated as a separate subdiscipline requiring specific standards and conventions of reporting its findings (Czarnik 1999).

Such a shift in the way chemistry was done was crucially underpinned by an assemblage of methods and instruments originating from a broad range of disciplines, ranging from computer science, robotics, semiconductor instrumentation, molecular biology, and organic chemistry. Geysen and colleagues point out:

Combinatorial chemistry is best described as the industrialization of chemistry; the chemistry has not changed, just the way in which it is now carried out, which is principally by exploiting instrumentation and robotics coupled to the extensive use of computers to efficiently control the process and analyse the vast amounts of resulting data. (Geysen et al. 2003, 222)

The availability of improved and innovative instrumentation from other disciplines, such as microarrays, synthesizers, semiconductor chips, binding substrates, different fluorescent markers, photolithographic instruments and scanners, was central to the development of combinatorial chemistry as a novel scientific practice and the subsequent dissemination of its techniques to other research tools, most notably in the forms of DNA microarrays and gene chips (Lenoir and Giannella 2006). Reflective of its multidisciplinary origins, combinatorial chemistry encompassed a

\footnotetext{
${ }^{32}$ Interestingly, Geysen, who is listed as the inventor or co-inventor of twenty U.S. patents, did not patent his break-through invention in 1984 as a process patent, but rather claimed the patent for products associated with the technology: the synthetic peptides, vaccines, and diagnostic testing compositions containing these peptides (Application under the PCT filed on 8 November 1984; US patent 4,708,871 granted on 24 November 1987). Geysen's first patent application which claimed the peptide solid phase synthesis method was filed on 16 February 1990 under the PCT and granted on 23 July 1996 as US 5,539,084.
} 
broad range of methods, objects, and instruments: library synthesis methods, the libraries themselves, screening or characterization methods, equipment and software, and materials resulting from synthesis (Symyx 1999, 37). Most importantly perhaps, characteristic of post-genomic technoscientific assemblages (Nowak 1995; MüllerWille and Rheinberger 2009, 118-135), computational and scientific practices have been inextricably intertwined in combinatorial chemistry.

To the IPC classifiers, such an ensemble of material and immaterial practices and instruments posed considerable challenges, not the least because the nature of combinatorial chemistry seemed to lack a unique inventive feature and precisely presented itself as a combination or assemblage of different elements without a "core" subject matter. The following interlinked aspects needed to be taken into account: first, the novel synthesized molecular probes could be useful. However, the whole collection, i.e. the prepared microarray or library, could be significant, too. This is because the synthesized probes are normally of such small quantity that their importance lies rather in the information they embody. ${ }^{33}$ Therefore, the central utility of combinatorial chemistry could lie in the library as a whole as a collection of synthesised probes. Increasingly, libraries have been exclusively "virtual" in the sense that the probes exist only in digital representations in a computer or computer-readable medium (Annex 24, 2). The definition and meaning of a combinatorial library were ambivalent as it could denote both material and immaterial properties. ${ }^{34}$ As a result, in order to classify combinatorial chemistry, the IPC working group had to grapple with questions, such as: does the proper subject matter consist of single probes or a collection of probes? Are they chemical or informational? Does screening precede identification? Do instruments precede the library or are these two inextricably linked together?

\section{Documentation and process}

With the task of creating a new subclass for combinatorial chemistry, the IPC revision project C422 began in April 2000 and was completed in July $2004 .{ }^{35}$ A special working

\footnotetext{
${ }^{33}$ I am grateful to Ursula Klein for pointing this out to me.

${ }^{34}$ Similar difficulty exists in the area of patenting biological information embodied in computer-readable format, something which became apparent in the case of the patent application by Human Genome Science for genomic data in a computer-readable format (as discussed in Eisenberg 2002, Pottage 2006, and Bostanci and Calvert 2008). According to Bostanci and Calvert, one ground for rejecting the application was its unclassifiability, but it seems that the problem was a lack of unity or multiple inventive subject matter in the application, which is a different legal concern.

35 The hierarchical structure of the IPC consists of the following: section (e.g. C for chemistry); class (e.g. C40 combinatorial technology); subclass (C40B combinatorial chemistry); main group (e.g. C40B 40/00 Libraries per se); and then different hierarchies of one-dot (e.g. C40B 40/04 · Libraries containing organic compound); two-dot subgroups (e.g. C40B 40/06 Libraries containing nucleotides or polynucleotides, or derivatives thereof); etc.
} 
group (Subgroup D) consisting of patent officers of regional and national patent offices was appointed by the normal IPC Revision Working Group in 2001 for creating a new place for combinatorial chemistry $(\mathrm{C} 40 \mathrm{~B})$ in the IPC. It formed the main locus of the actual classification work by writing recommendations and drafting numerous classification schemes over four years, which were subsequently submitted for adoption to the Committee of Experts. The result of the working group was incorporated as the subclass C40B in the eighth version of the IPC, which came into force in 2006. The corresponding US patent class 506 was established on 2 October 2007. ${ }^{36}$

This case study on the classification of combinatorial chemistry is based on my reading of the revision project $\mathrm{C} 422$ documents containing communication between the patent office members of the working group. These were posted by participating patent offices via internal list-servers onto the IPC e-forum, which functioned as an electronic group discussion and documentation forum in addition to the twice yearly working group meetings. ${ }^{37}$ Described as one of the "critical business applications for the IPC" (WIPO 2012, 7), the IPC e-forum is an electronic platform which was established by the WIPO in 2001 in order to improve the flow of information and work between patent offices by storing all the files of IPC-related projects. As encouraged and mandated by the Committee of Experts in 2002, the e-forum is the only official forum of communication and discussion besides the yearly meetings in person. ${ }^{38}$ As a constantly expanding platform of documentation of IPC work, it represents a fascinating current and historical resource for gaining insight into the dynamics of the classification process and communication between different offices. ${ }^{39}$ Currently, as of April 2012, it has expanded into a full-fledged database containing records of 1175 completed IPC projects, as well as 236 ongoing ones.

The project folder on combinatorial chemistry forming the basis of the present case study contains ninety-two documents (annexes). ${ }^{40}$ My interpretation of the annexes, the Committee of Experts reports, and the different versions of the subclass C40B before its final incorporation into the eighth version of the IPC, is as much based on the cross- references to each other's proposals, comments and decisions, as much as it is

\footnotetext{
${ }^{36}$ Classification orders are available at: http://www.uspto.gov/web/offices/opc/coi/classes501-520.htm (last accessed February 15, 2009).

${ }^{37}$ http://www.wipo.int/ipc-ief/ (last accessed August 12, 2012).

38 "Discussion of IPC revision projects and of other tasks of the IPC Revision Working Group is carried out electronically, through submission of proposals and comments to the IPC electronic forum which is structured with regard to major activities of the Working Group, such as revision projects, definition projects, translation projects. ... In the future, activities of the ad hoc IPC Reform Working Group and certain tasks which could be carried out by the Committee of Experts itself will also be incorporated in a structured form in the IPC electronic forum. The forum will become a central place for discussion of all activities concerned with the development of the IPC" (WIPO IPC Union Committee of Experts Report of Thirty-First session, 24 January $2002[\mathrm{IPC} / \mathrm{CW} / 31 / 7])$.

${ }^{39}$ The currently ongoing project CE445 initiated in 2012 is concerned with the improvement of the e-forum for patent office users.

${ }^{40}$ Access through http://www.wipo.int/ipc-ief/en/project/13/C422 (last accessed August 13, 2012).
} 
informed by the lack of comment and varying levels of engagement. Listed in reverse chronological order from April 2000 until July 2004, the annexes were written and posted in English by all working group members, with additional separate publication of French translations of draft classification proposals and working group decisions. Thus a substantial part of the classification work was carried out online, removed from the physical spaces of the patent office. This was only possible because patent documents themselves were converted into electronic form and accessible through databases.

The annexes themselves comprise ten project rapporteur reports, six draft proposals, sixty-three comments by participating patent offices, and nine IPC revision working group decisions. As the Committee of Experts were free to adopt or to reject the subgroup recommendations, the annexes (except for the working group decisions) are not official legally binding documents, but read like informal memoranda in their form and writing style. In contrast to the Committee of Experts reports, which were consulted in conjunction with the C422 project files and which resemble formal protocols not giving any indication about the processes behind decisions, the working group annexes contain profound disagreement amongst the group members on substantive and structural issues. Previous positions and drafts are openly criticized and discussed. Especially in the first two years of the project in which the substantial classificatory order was put in place, the annexes resemble argumentative essays where different understandings of the scientific practice were laid bare between the different offices.

\section{Actors and working group process}

Revisions and modifications to the IPC are under the remit of the Special Union for the IPC (IPC Union), an international body representing the member states of the Strasbourg Agreement. It comprises an Assembly and Committee of Experts which meet annually. The institutional set-up of the IPC Union is rather loose and flexible depending on the agenda. There is an International Bureau devoted to the administration of the IPC within the WIPO structure, but the classification agenda is mainly set by the Committee of Experts, composed of member patent offices of the IPC Union, entrusted with the implementation and maintenance of the IPC. ${ }^{41}$ It suggests areas for reclassification, the creation of new classes, and appoints or delegates working groups for this purpose. More accurately, it is the participating member patent offices of the Committee of Experts, which initiate changes, shape, negotiate, decide, and apply the IPC in their ongoing practice.

The project on combinatorial chemistry was initiated by the UK patent office in 1999, which acted also as the rapporteur until 2002, after which it asked the EPO take

\footnotetext{
${ }^{41}$ Art. 5, Strasbourg Agreement. At the twenty-ninth session of the Committee of Experts in March 2000, at which the request for revision on combinatorial chemistry was made, there were twenty national members states present, as well as the EPO.
} 
over the role as it appeared to have the appropriate resources and expertise. ${ }^{42}$ Throughout the project the EPO was a central participant by providing many draft classifications and probing them by statistical analyses. The project workflow was divided into sixmonth-cycles, within which specific questions and drafts had to be commented upon. The actors of the Subgroup were patent officers from national and regional offices: ${ }^{43}$ some members of the working group were classifying examiners from their respective offices for classification (US, UK, JP), whereas others combined subject matter expertise in chemistry with classifying expertise (EPO) or examining experience (D).

In this respect, the classification expertise of the IPC differed significantly from its application in national and regional examining offices. There, search or examining officers, who examine patent applications, conduct classification on the job by assigning a patent classification to the incoming patent applications. The separate offices of classification are more concerned with the overall consistency and functioning of the classificatory system at large, but are rarely involved in the daily work of classifying. ${ }^{44}$ I had pointed out in the preceding discussion of the significance of the patent classification and its historical formation that the boundary between the classifying and examining roles is blurred and that patent examiners are still the main actors of classification at the frontline (Rampelmann 1996). Most notably, the IPC classification process was one step removed from the frontline of actual classifying practice carried out by the individual patent offices by being detached from the actual search and examining practice. This influenced the way in which the new class for combinatorial chemistry was devised, as I will show later, that is, by strong reliance on statistical modeling of patent documents rather than by a case-to-case analysis of their contents.

Although there is no expressed indication about the decision-making procedure in these meetings, the protocols of the Subgroup D stress that decisions were "unanimously adopted" despite lingering substantial disagreements. In contrast, the Committee of Experts' decision-making process was often pushed forward by majority voting (Art. 5 [6] Strasbourg Agreement). There was not a clear division of the working group into camps, although clearly the bigger patent offices, such as the EPO, US, Japanese, and German ones produced the longest and the most argumentative comments reflecting strongly held beliefs about the subject matter and how it ought to be classified. The following discussion of the substantive areas of disagreement will show that many of the disputed issues were resolved by an evaluation of file sizes upon "test driving" classification drafts. However, some fundamental disagreement about the

\footnotetext{
${ }^{42}$ Personal communication with UK Patent Office examiner Martin Price via email, 23 April 2012.

${ }^{43}$ The members of the Subgroup D included the European Patent Office (EPO), the United States Patents and Trademark Office (USPTO), and the British, German, Japanese, Swedish, Romanian, Russian offices.

${ }^{44}$ At the USPTO, for example, even when classification disputes arise due to difficulty in identifying prior art or because of an invention's hybrid nature, a Technology Center Classification Panel consisting of patent examiners from different Technology Centers resolves these disputes with binding force without the involvement of the Office of Classification (MPEP, $\S 903.07[\mathrm{~b}])$.
} 
subject matter could not be accommodated. The USPTO stood opposed to the EPO and German positions on the obligatory multiple classification rule for combinatorial chemistry until the end of the project (Annex 63, 3). Such irresoluble disputes seem to have been referred as unresolved matters to the Committee of Experts who would have decided by majority vote. ${ }^{45}$ Unfortunately, the relevant documentation of the Committee does not contain further detail on these processes.

The case study of the making of the new class does not so much try to find out what the patent classification contains, but rather how it came about. In other words, rather than engaging in a judgment of the degree of "rightness" of the law-science interaction and the legal definition of the technoscientific invention, I have been interested in the way in which substantial disagreements about the scientific subject matter have been dealt with and became incorporated in the resulting legal classificatory scheme. As in some analyses of patent litigation (Cambrosio, Keating, and MacKenzie 1990; Jordan and Lynch 1998; Swanson 2007), I had initially expected the patent officers to unpack the law-science hybrid by engaging with the latest scientific literature or consulting experts in combinatorial chemistry. However, the project files unmistakably suggested that the working group was more concerned with legal-internal considerations of search and file management than with the technical artefact "itself." The working group documents contained little reference to non-patent literature or scientific papers, except on four occasions, all of them raised by the EPO. ${ }^{46}$ USPTO submissions refer to "experts" on several occasions, but it is not clear whether they denote in-house experts, that is patent examiners, or scientists working in the field.

As I now turn to the numerous differences in understanding combinatorial chemistry by the classifying officers, I demonstrate that these were not resolved by agreeing substantively on the nature of technology, but by recourse to statistical modeling. The IPC's meta-referential function involved a different kind of materiality and practice than the ones which had characterized the historical development of classification. I argue that the digital representation of patent document and statistical calculations of their hypothetical numbers for different draft proposals constituted the key techniques in the making of the new classification for combinatorial chemistry.

\section{What is the invention?}

In the context of combinatorial chemistry, the massive number of patent applications and issued patents attests to the early inventive and vigorous patenting activity in the

\footnotetext{
${ }^{45}$ Personal communication from Heiko Wongel of the EPO who was the chair of the subgroup D by the end of the project, summer 2007.

${ }^{46}$ Most explicit was the reference to scientific publications together with patent documents by European Patent Office in Annex 29 (referring to, e.g. Geysen et al. 1996; also references to scientific journal articles in annexes 33,54 , and in 59).
} 
field (Gibbs 2001; Rouse and Hardiman 2003; Lenoir and Giannella 2006). Scientists both in commercial and academic sciences pursued patents at such a high rate that patent officers saw the need to create a new patent category. "High activity for subject matter that cannot be classified in present IPC" was stated as the reason for requesting a new creation of a subclass for combinatorial chemistry. ${ }^{47}$ The sheer number of patent applications effected a legal perception that a new technological artefact was emerging, which was not classifiable in a coherent way within the existing grid.

It is difficult to pinpoint the exact causes for such fervent patenting activity in combinatorial chemistry. Authors, such as Wright (1986), Kenney (1986 and 1998), Rabinow (1996, 20-9), and Sunder Rajan (2006) have pointed to the favorable constellation towards biotechnology patents from the early 1980s, which was characterized by the introduction of the Bayh-Dole Act in $1980,{ }^{48}$ the substantial rise in venture capital, multinational and government funding of science, together with the 1980 US Supreme Court decision in Diamond v Chakrabarty (447 US 303, 100 S. Ct. [1980] 2007; also see Kevles 1994). In the context of combinatorial chemistry, two particular aspects stand out from the general political, legal and economic constellation after the 1980s. First, combinatorial chemistry technology is particularly useful for pharmaceutical industries, thereby placing an important role on patent. By considerably accelerating the steps of screening and identification for useful properties necessary in the upstream drug-development process, combinatorial chemistry techniques embodied the promise to reduce the financial risks posed by the investment-heavy, long and potentially fruitless lead-drug discovery processes by permitting the rapid synthesis and screening of a large number of compounds (Terrett 1998, 3-5).

The subject matter of combinatorial chemistry, moreover, fits well into existing legal concepts of what constitutes a patentable subject matter. The description of combinatorial chemistry as the "industrialisation of chemistry" (Geysen et al. 2003) alludes to its imminent patentability, which doubly fulfilled the patent requirements of being a chemical substance (Eisenberg 2002; Pila 2003) and being mechanically reproducible (Pottage 2006; Pottage and Sherman 2007). Thus, they constituted patentable subjects par excellence, combining chemistry and mechanics within a single technological practice.

However, despite what seems to be a very patentable subject matter, the classification working group grappled with its definition. In the first year of the working group, the USPTO wrote that "a consensus on the definition of combinatorial chemistry" had to

\footnotetext{
${ }^{47}$ Request for Revision of the IPC (IPC/C422 Annex 1). The request can only be made on a form which specifies three possible categories of reasons for request (x-notation, clarification of wording, other reasons which may be accompanied with information about (a) file size, for example the number of documents unclassified, (b) rate of growth (again in terms of the number of documents) and (c) activity, which is defined as searches per year.

${ }^{48}$ On the effect of 1980 Bayh-Dole Act, which allowed the patenting inventions stemming from governmentfunded research by universities, see Rai 1999; Eisenberg and Rai 2003.
} 
be reached before proceeding further (Annex 9). The Japanese Patent Office went even as far as to attempt to capture the invention in a detailed textual definition outside the draft classification order, despite (or perhaps precisely because of) its acceptance that "there is no common recognition what 'a central problem in combinatorial chemistry' is among the industry, and it would change with technological progress" (Annex 14). Two years into the process, there was still no agreement about what constituted various forms and steps of combinatorial "synthesis":

After reading EP's explanations of the different combinatorial syntheses, US understands what EP intends liquid phase, solid phase, and mixed phase to be, but we are not certain that these concepts are universally interpreted in this manner by others. US examiners do not interpret these concepts in the same way. For example, EP appears to be interpreting a mixed phase system more broadly than US examiners interpret it. (Annex 63)

The need to define the nature of the subject matter stemmed from the IPC requirement that inventions should be defined by reference to "their intrinsic nature" rather than with respect to their utility or "applications" (WIPO 1995, §68-71). Moreover, an invention was to be classified as a "whole," which was difficult in cases of inventions involving a combination or a larger system such as in the field of combinatorial chemistry (WIPO 2008, $§ 91, \S 100$ ). Determining an invention's rightful place within the patent hierarchy was closely linked to the answer to the question: what is the invention?

There were two central disputes running through the classification process. The first was whether a combinatorial library was essentially chemical or digital in nature, or both. The second dispute was about whether such a library constituted a unitary whole or whether it was a collection of parts. As in the case of biotechnology patents involving computer-related inventions (Eisenberg 2002; Pottage 2006), both disputes revealed the legal path-dependency on its existing epistemic categories, as well as the different legal patent regimes relating to computer-related inventions in Europe and the US. I present these arguments in turn.

In the context of combinatorial chemistry, a library could denote both a combination of chemical compounds, as well as "virtual," digitized information resulting from them. The question was hence whether the essence of libraries resided in their material constitution or in the information embedded in them. Most working group members approached the new technology as falling within the chemical paradigm, which has been the theoretical premise underlying the patenting of biotechnological inventions and living matter since Chakrabarty. Especially the US and Germany differed in their understanding of a library's nature and scope. Particularly, the term "virtual libraries" posed the question of whether it should belong here in section C concerning chemistry, or elsewhere in classes dealing with computer-type inventions. In the discussion, two types of virtual libraries were identified: virtual libraries enabling computer generated simulations and virtual libraries directing combinations and recombinations of actual 
molecules to form transient species ("directed molecular evolution"). The German patent office repeatedly opposed the wording "virtual" in principle and wanted it removed from the IPC. In contrast, the USPTO and EPO were in favor of including virtual libraries into the subclass title, which could include digital representations.

The disagreement about whether "virtual libraries" constituted a patentable matter reflected the difference in legal doctrines regarding the patentability of computerrelated inventions in US and European jurisprudence. Whereas business methods and related software is patentable by US law, ${ }^{49}$ in Europe, the European Parliament rejected a draft directive on software patents twice amidst much political controversy in 2005 . In the end, virtual libraries were added to the title for combinatorial chemistry, but in a somewhat unresolved manner. Whereas the definition of combinatorial chemistry was firmly anchored as a chemical kind, as "a set of compounds (a library) prepared by combinatorial synthesis," some leeway was left open to include digital libraries by the enumerative title: "C40 B Combinatorial Chemistry; Libraries, e.g. Chemical Libraries, In Silico Libraries." The insertion of "e.g." reflected the compromise which left the definition of library open to further interpretation and future technological development.

The disagreement resulting from the application of chemical analogy to combinatorial libraries continued in a different context that involved the analogy between such libraries and a Markush-type chemical invention. ${ }^{50}$ A Markush claim is a method by which multiple patent claims can simultaneously be made for a group of chemical compounds by indicating any possible substitutes within a general chemical formula. ${ }^{51}$ Whereas the USPTO understood the library to constitute a "unitary" whole, the EPO and the rest of the working group regarded it as an assembly of many distinguishable parts, and therefore analogical to a Markush-type chemical formula. The German patent office submitted:

Chemical libraries as such are often identical to chemical compounds expressed by general chemical formulae. [They], characterised by their chemical nature should be classified in the existing groups for chemical compounds. (IPC /C422 Annex 5)

In the view of the USPTO, however, the ability to manipulate and to recombine rather than the individual compounds or library members themselves, was seen as the key inventive value of a combinatorial library:

\footnotetext{
49 State Street Bank v. Signature Financial Group 47 USPQ2d 1596 (Fed. Cir. 1998).

${ }^{50}$ Chemical inventions underlie separate classification rules. Chemical compounds are classified according to their chemical structure (WIPO 2006, §93), and mixtures, preparation, and apparatus, whereas articles underlie specific instruction as to their classificatory places. More complicated are rules for general chemical formulae, such as "Markush"-type compound claims, but put simply, they are made at different appropriate places for each inventive compound $(\S 100)$.

51 The US MPEP states: "A Markush-type claim recites alternatives in a format such as "selected from the group consisting of A, B, and C” (see Ex parte Markush 1925 C.D. 126 [Comm'r Pat.] 1925).
} 
Combinatorial libraries should be classified differently than Markush-type compounds. Some offices liken libraries to Markush groupings of compounds. In our opinion this is clearly not the case; libraries are clearly distinct ... A claim to a library, on the other hand, encompasses the entire library as a single unitary entity. (IPC /C422 Annex 18, p. 4)

Such different understandings of the object exerted direct consequences on how it ought to be classified. Depending on what one understood the nature of the combinatorial library to be, the applicable principle of classification would differ. In line with the chemical analogy, most patent offices, and in particular, the EPO, advocated obligatory multiple classification places for the combinatorial library, so that the individual chemical compounds, which have important functions within a library, ought to be classified in their usual IPC compound places in addition to their place in C40B. With the transfer of the IPC from paper to a digital platform, such multiple classification and hyperlinking of patent documents could be done with relative ease, which would have been much more difficult with paper documents. The USPTO stood opposed to such obligatory multiple classification.

Classificatory principles were thus not only influenced by different understandings of the subject matter: digital material conditions and technical possibilities played crucial roles in shaping classificatory hierarchy and boundaries by allowing testing draft classification schemes by modeling and simulation. Before I present such ways in which the classification was simulated and modeled, I will analyze the way the new class categorically stabilized the identity between the invention and the patent document.

\section{Patent documents as inventions}

The first document of the working group files contains the initial revision request for the creation of a new category for combinatorial chemistry and the following reply from a senior examiner of the UK Patent Office:

Being a totally new subclass, I thought it was a great opportunity to try our proposed new format for subclasses. I have therefore devised a very sparse subclass with allied classification definitions for the subclass and various main groups. It is my intention to hyperlink the various definitions to the relevant parts of the schedule to which they relate but I haven't actually made the links as I thought they would not translate to Word format. ...

I'm sure you and all my colleagues in IPC will let me know what they think of a somewhat experimental project! (Annex 1)

Indicative of the highly internal and utmost practical concerns dominating the working group correspondence, the excitement was not so much about the novel subject 
matter to be classified, but about the opportunity to apply new classificatory rules to a new subclass and about the infrastructural possibility (hyperlinks) and anticipated technical restraint (the usual Word format problems) in document circulation. Indeed, the organization of patent documents for legal administration was the most important objective of the classification exercise. Underlying such an administrative aim was the premise that the very nature of combinatorial chemistry was embodied in patent documents.

The construction of the state of art of combinatorial chemistry illustrates how patent documents were equated with the technoscientific practice itself without the need for mediation. State of art, or also called prior art, is the legal term for the current state of scientific and technological practice in an inventive field. For classification, the estimation of prior art is significant because, depending on the perceived complexity and evolving speed of technology, the level of subdivision within a subclass would vary, as would the hierarchy of classification: relatively stable technologies might be better classified in the order of the most general to the most detailed, whereas it would be more practical to order quickly evolving technologies from the most complex to the more general. There was profound discord amongst the working group members about the level of the state of art, which is expressed in the correspondence of the UK patent office after the circulation of a detailed US proposal:

We are a bit confused about the US counter proposal as we thought that the Revision working group agreed that submissions should be based upon a main group only subclass as the technology was not yet defined enough to subdivide any further. The US counter proposal obviously goes much further than the equivalent of main groups and as such we could not support it. (IPC/C 422 Annex 4; emphasis added)

In order to get a better sense of the state of art, the working group proceeded in two ways: it would deduce prior art by the contents of the patent applications received and by the number of patent applications which were difficult to classify. The patent document, or more precisely, the claims made in the patent document, constituted the subject matter to be classified so that the answer to the question of "what is the invention as a whole" was to be "found in the claim disclosure of the patent documents in this technology" (Annex 9). The object of classification, in such a view, was not the invention or the inventive subject matter, but rather the object's representation in the claims of a patent document.

The working group estimated the state of art by counting patent documents. The equation between the invention and its textual representation can be seen in the following: at one point, the EPO was invited to provide examples of patents on virtual libraries, in order for the other working group members to obtain a sense of what kind of objects they might involve. The examples were provided in the form of patent document numbers: "EP-1130009; US-6295514; WO-0150124 ..." (Annex 46). Thus the legal embodiment of the actual invention with the patent 
document effectively resulted in the invisibility of the actual material invention after its legal textual reconstruction and classification:

The proposed scheme is based on an internal USPC classification schedule that was developed by examiners and classifiers utilizing large numbers of patented documents for testing classifications. This enabled our classification scheme to be tested under real world situation. Our classifications have been refined and defined to the point where our examiners are currently placing newly published combinatorial chemistry patent documents into them. (Annex 9; emphasis added)

Here, the testing of how USPC classification worked when patents were placed into the scheme became equated with a "real world situation." However, "real world" referred to "newly published combinatorial chemistry patent documents." In this sense, the textual embodiment of inventions and its classification came to be interlinked to form a kind of hybrid world between virtual and actual elements, in which the "real" was taken as the world of legal actors, both human (examiners) and non-human (claims in the patent document) by which a model scheme was tested.

Such a highly internal perspective on what constitutes inventive activity reveals the assumption of a truthful correspondence between the technoscientific invention and its textual reconstruction by the patent claims. The patent officers in the working group operated on the premise that, by classifying existing patent documents, they were simultaneously classifying the very scientific objects for which patent rights were sought. As a result, classifying patent documents was equated to classifying general inventive activity in the field of combinatorial chemistry. After the actual invention itself was "eclipsed" (Strathern 1988, 155) by its legal reconstruction in patent claims, the new patent subclass for combinatorial chemistry consolidated the very textual legal inventions as an inventive kind.

\section{Modeling the inventive kind}

The implication of the centrality placed on patent documents is that it becomes important to take into account the material condition and technology of classification. The material setting in which the IPC is embedded plays a significant role in the structuring of the new class. As an overarching reference network connecting various existing patent classes, the IPC operates in a very different material and institutional environment from the historical development of patent classification, which was marked by acute material and spatial constraints, as described at the beginning of the article. In particular, the IPC is characterized by relative immateriality in terms of patent documents and their storage, as it is not linked to a material depository 
system. ${ }^{52}$ Since 2007, the IPC has been published only in digital format (WIPO 2007). The Master Classification Database, a bibliographic database enabling the search of all patent documents according to their IPC symbols, can be accessed via the IPC's link to Esp@cenet, the European patent online documentation. ${ }^{53}$ As a hyperlinked metareference system, the IPC is relieved from concerns of material paper and digital storage because the bulk of actual storage, search, examination, and archiving of the patent documents is carried out by the individual patent offices. ${ }^{54}$ Whilst a huge computing infrastructure underpins the digital nature of IPC, linking it to the various regional and national patent databases, the issues of materiality and space are categorically different in its quality and scale from the ones discussed in the 1920s and 1930s.

One notable effect of IPC's relative immateriality has been the possibility of "testing" classification schemes by modeling and database computation of existing patent documents, instead of having to physically carry patent documents between different rooms and rearrange them spatially. In the creation and structuring of the new subclass for combinatorial chemistry, a mixture of statistical simulation and administrative judgment played an important role in accommodating disagreements about the nature of combinatorial chemistry, as for example, in the dispute about defining the steps of screening and identification.

In combinatorial chemistry, the processes of screening and identification were often intertwined and escaped functional priority: material probes prepared in arrays, also called libraries, underwent the process of screening for useful properties, which necessarily involved a prior identification of particular molecular structures or properties as being useful. On the other hand, single synthesized probes could also be singled out from a library after synthesis and be subjected to a more detailed identification of its substance. Not surprisingly, the working group members of the classification group wrestled with the difference between screening and identification:

... we wonder how the difference between screening ... and identification ... should be defined. Our interpretation is that screening is a way of choosing a substance or a group of substances from its application or functionality and that the term identification aims at the chemical constitution of a substance or a group of substances. (IPC/C 422/00 Annex 8)

\footnotetext{
52 The International Bureau of the Patent Cooperation Treaty (PCT) at the WIPO acts as a receiving office for PCT patent applications and therefore operates a filing system based on the IPC. However, the proportion of the PCT applications received by the Bureau is small (6 per cent) in comparison to the main recipients of the bulk of the PCT applications: the US (33 per cent), EPO (18 per cent), and Japan (17 per cent) (WIPO 2008b). ${ }^{53}$ Esp@cenet can be accessed through < http://www.espacenet.com/index.en.htm > (last accessed August 12, 2012).

${ }^{54}$ National and regional patent systems, such as the USPTO and EPO, increasingly operate digitally by electronic submission and processing of patent applications. The PCT Bureau only accepts electronic applications. At the USPTO, the filing and documentation of a patent application process is increasingly stored in the "Virtual Image File Wrapper" which can be accessed from the desktop of the patent examiner and which is linked to an electronic infrastructure of Office Action Correspondence Subsystem (OACS), which gives details about forms to be filled out (MPEP $§ 903.07)$ and searches to be documented (MPEP $§ 719.05)$.
} 
Arguments about the meaning of the invention went hand in hand with arguments about the classificatory order. For example, the Japanese patent office insisted that screening and identification were both inseparably interlinked in practice, and were therefore hard to classify: "It is difficult to clarify the purposes of inventions whether screening or identification when their characteristics are apparatus and detecting method itself (e.g. a method using optical sensor), and is also hard to classify them" (IPC/C 422 Annex 43). Similarly, the German office wrote: "There is not a welldefined borderline between screening and identification of selected products. ... Therefore we prefer to combine the proposed two main groups in one main group" (IPC/C 422 Annex 16).

Unable to reach a consensus on these matters, the more practical rationale of managing patent documents served as the decisive criterion for defining the classification order. The consideration of file size played an important role. Relatively early in the working group process, one year after its beginning, the EPO was asked to apply the draft classification scheme to existing patent documents:

EPO was invited to provide the potential file size of the main groups. ... These are in-file documents only, so the numbers are greatly underestimated.

$\begin{array}{ll}1 / 00 & 2000 \text { documents } \\ 3 / 00 & 2000 \text { documents } \\ 5 / 00 & 650 \text { documents } \\ 7 / 00 & 200 \text { documents ... }\end{array}$

(Annex 33)

As a result of EPO's estimation, the working group decided to subdivide the main groups further: "In light of the potential file size of main groups of subclass C40B, the Working Group agreed that certain subdivision of main groups was needed" (Annex 45). For example, there was the concern that a proposed subgroup would be underpopulated and therefore redundant: "the new 11/00 main group will have no patent documents if both 11/02 and 11/04 are created. US recommends deleting 11/02 and 11/04 in order that 11/00 will be populated with documents" (Annex 63, 3). An even distribution of patent "population" across the categories constituted one of the main reasons why screening and identification were separated into distinct groups.

These demarcations prompted a change in the classificatory order, which led to substantial reshuffling, thus creating quite a different meaning of the inventive artefact:

After identification, we then placed screening, libraries, creating, apparatus, and miscellaneous groups, which is based on more complex to least complex subject matter. Our suggested scheme order change has moved Identification and Screening higher in the scheme. (Annex 47, para. 14)

As a result of the change in classificatory hierarchy, several patent documents changed their place, and thus their relational identity. For example, in the final classification 
scheme, the US patent 5,565,324 "complex combinatorial chemical libraries encoded with tags" assigned to Columbia University and Cold Spring Harbor Laboratory became part of the "specially adapted identification group," whereas it was previously classified under screening (Annex 47, para. 16). The relative place of an invention within patent classification is arguably more indicative of its identity than its name. The identity of a group or class of invention is relationally defined by reference to its position within the IPC hierarchy, without the need to agree on the essence of the subject matter. In patent classification, class names or titles are not exclusive and therefore do not ascribe singular identity to the inventions (WIPO 2006, §45). A patented invention can belong to multiple patent classes and contain cross-references, synonyms, examples, and multiple listings across the board. ${ }^{55}$

As much as the potential file sizes played a crucial role for resolving substantial, as well as the formal classificatory issues, there was also a "sense" of which types of inventions ought to be grouped together, which was based on existing patent documents. Thus, a test application of a proposed scheme by the USPTO revealed that too many patents would be categorized as methods of screening rather than being categorized as methods of identification.

Upon placing several hundred patent documents, we found the scheme was not working as well as we would like, especially concerning identification and screening. We were getting many patents in the screening area which would better go under identification. By moving the identification group before screening we can be certain to collect the methods specially adapted for identifying library members. ... Significant identification methods in the combinatorial area will now not be lost under screening. (Annex 47, para. 11)

As the above statement implies, a "sense" of a well-working scheme may have been grounded in a certain understanding of the technological background, the result of trained judgment of recognizing similarity relations or "family resemblances" without having to come to an agreement about the essence of property of an artefact (Wittgenstein [1958] 1991, 52-3; Bloor 1982, 271). The IPC working group practice reflects and affirms Wittgenstein's argument that a group of objects is formed by reference to family resemblances rather than having a single property in common. Whereas Kuhn (1970) pointed to the central role of exemplar in the constitution of scientific communities by training similarity perceptions and serving as a means by which they are sustained - if one could speak of an exemplar for assigning an IPC class, at all - there was not a unique exemplar or an ideal inventive type (Douglas and Hull

\footnotetext{
55 The IPC 8 introduced multiple classification, which can be either multi-aspect classification or secondary classification. Moreover, there are hybrid classification systems, which include indexing schemes linking additional aspects deemed relevant with the main classification. In the case of hybrid systems, it does not seem clear what kind of status the indices occupy, especially in relation to the subclass (see chap. 11, Guide to the IPC9 [2008a]).
} 
1992), but rather an aggregate of inventions represented by patent documents, which had not yet been classified or had to be re-classified. The IPC working group defined the ideal inventive kind by experimenting with various draft classification schemes with computational models, which in turn enabled them to refine and to reconstruct the common trait perceived in existing patent documents.

\section{Conclusion}

In the context of the making of a new IPC class for combinatorial chemistry, the creation of the new patent class was an unequivocal reflection of scientific novelty in law, which was reflected in the high number of patent applications received. Here, legal change was propelled by the proprietary initiatives taken by scientists. However, beyond such an initial scientific "input" at the interface of patent documents, the case study has shown that there was hardly any epistemic or practical interaction between law and science in the making of a new patent category. Patent classification was seen as an utmost practical necessity and material tool to organize patent documents for search and examination. Taking into account the historical development of patent classification within patent administration, I have argued that the lack of interaction stems from the specific space of representation (Rheinberger 1997, 102-13) in patent law, or more specifically, I would add, from the legal reconstruction of the inventive idea by textual claims. These in turn are organized by patent classification into material, and increasingly immaterial, bureaucracy. That is why patent classification represented "the central storehouse of the accumulated technologic experience" (Rossmann 1934). From the viewpoint of the classifying officers, science was already "inside" the law. Thus the classification of patent documents was seen as equivalent to the classification of technoscientific inventions without a need for remediation. Although patent classification modeled and materialized the inventive idea as a proper kind to be administered, the actual technoscientific invention remained invisible in patent classification.

As a way of conclusion, I wish to situate these findings within the broader scholarship on patents and, in particular, raise questions and rethink the notion of patents as hybrid networks.

Scholars in socio-legal and science studies have described patents as law-science (Bowker 1992; Hilgartner 1998; Edmond 2001) and culture-nature hybrid networks (Strathern 1996; Pottage 1998) or as a vector (Sherman 1994). The benefit of understanding patents as hybrid entities is that one becomes attuned to their specific discursive underpinnings and conditions of material constitution. Such an approach emphasizes that the legal category of a patent right is not a rigid one, but that it has to be examined "inside-out" (Riles 2001): both from the inside of law, understood as a set of specific norms and stabilizing practices, as well as from its social "outside," that is, from the perspective of science, technology, politics, and economy. The inside-outside 
distinction could be equally reversed depending on one's point of observation. In this regard, Pottage and Sherman described in detail the destabilization of patent categories by biotechnological practices and the accompanying legal engendering of biological categories (Pottage 1998; Sherman 2008; Pottage and Sherman 2010). For Pottage, legal and biological instrumentality applies in both complicated ways (Pottage 2006). Such an "inside-out" approach has also underpinned studies that have examined the social and historical construction of patent legal categories and practices as objects of history of science (Biagioli 2006; Swanson 2009). In a similar fashion, I hope to have shown with the above analysis that, as scientific objects have their own trajectories, the legal and administrative enactment of a patent category is shaped by specific and shifting material and discursive constellations.

Whilst I agree with the characterization of patents as hybrid entities, what I wish to re-emphasize is that it takes both legal epistemic categories and specific technoscientific practices to make a patent network. The findings of this article offer the opportunity to question and to rethink the relative "density" or "articulation" (Goodman 1968) of such a hybrid network, which I understand simultaneously as a question about the degree of openness or reticence of law-science interaction and the durability or instability of law-science co-production (Jasanoff 2003, 20). The patent classification process described here sketches a significantly less fluid picture of a patent's hybridity. The making of the new IPC subclass shows that patent classifications do not represent an archive of past inventive scientific and technological objects, but rather patent law's textual constructions of the former as patent claims. The case study demonstrates that identity was assumed between the patent document, the inventive idea as inscribed in the patent claims, and the actual technoscientific object. ${ }^{56}$ Such an assumption of identity throughout the classification process stands in contrast to insightful analyses by Myers (1995) and Swanson (2007), both of whom have emphasized the difference between drafting a patent document as a specific textual strategy and writing a scientific paper. Patents, in their analyses, were mediated strategies rather than objective mirrors. However, in this context of making a new patent class, there was not the same degree of epistemic interaction and friction as one might have expected from such an exemplary site of stabilization of hybrid legal and scientific knowledges. This result suggests that the character of a patent's hybridity varies considerably along different points of the network.

Such a lack of interaction between science and law cannot simply be interpreted as legal purification or boundary work (Gieryn 1983), by which technoscientific knowledge is molded or intentionally ignored to suit legal interests. The above analysis of patent classification sketches a picture of patent law's institutional and material infrastructure, which is built on the foundation of the legal blackbox of a patent

\footnotetext{
${ }^{56}$ As pointed out before, plant patents underlie different representational regimes and classification, which appear to be much more hybrid than the utility patents (see Sherman 2008).
} 
document and its administration by its classification. However, "blackboxing does not mean just setting aside" (Rheinberger 1997, 30). There are two main implications.

First, the assumption that patent documents embody the state of science and technology does not necessarily imply that patent law subscribes to or favors a specific version of science, be it unitary science or plural sciences. Rather, the analysis of patent classification confirms the argument that classes are bound by conventions and do not necessarily need to be true (Douglas [1966] 1991 and Douglas and Hull 1992; Goodman 1978). Patented inventions do not necessarily need to be scientifically "correct" (Bloor 1982). Until the validity of a patent is perhaps contested by litigation (Cambrosio, Keating, and MacKenzie 1990; Jordan and Lynch 1998; Swanson 2007), the relationship between the invention and its representation inside the blackbox of patent document remains untested. And even this may be purely played out on the level of legal written inscriptions as a question of the permissible degree of deviance between the written description of the inventive idea and the patent claims. Thus the classic tenet of Durkheim and Mauss that natural classifications are reflective of social organizational structures can also be applied to the IPC, albeit in a modified form the movement of knowledge is not necessarily from the social to natural, but from social to social. The organization of patents is based on social, especially institutional, conventions (Bloor 1982; Douglas and Hull 1992).

Second, despite its decidedly administrative purpose and design, the transfer of names of artefacts across from the scientific domain into patent classification exerts consequences on the meanings and uses of technoscientific artefacts beyond its material use within patent administration. The act of classification engenders novel associations and relations between inventions, which may not have been previously drawn, and thus stabilizes novel identities that may spill into non-legal fields. Combinatorial libraries came to be understood as being analogical to general chemical formulae and as assemblies of parts rather than as unitary wholes with a mainly informational value. In this light, the working group on combinatorial chemistry constituted an unofficial site of scientific classification; however, it was one which was highly internally determined.

The insight that the patent network is less hybrid at the point of the classification can offer some explanations about why the patent law system seems to have difficulty in adapting to novel scientific and technological developments (Eisenberg 2002; Pottage 2006) and why it proves so resistant to change by ad-hoc policy measures (Biagioli 2006, 1161). Precisely because patent law understands itself to be co-evolving with the sciences, it does not regard itself to be external to it or separate from it. Therefore, in a somewhat parasitical way, it also regards itself to be ruled by "the indisputable fact of novelty" (Daston 2000, 5) which marks modern sciences. Paradoxically, however, it is the very legal self-understanding of its "openness" or hybridity that makes the patent law system closed to technoscientific knowledge. The IPC's assumption of a mirror-like relation between an invention and its legal reconstruction in the patent document raises many questions about its use for the routing and examination of patent applications. The visibility and patentability of a novel invention will depend on 
the existing classificatory grid which determines its administrative routing. By design, the default assumption of legal folding-in of technology and science makes it more challenging to accommodate less stable or competing kinds of knowledge claims as patentable.

As a result, I would argue that the widely accepted and valid notion of patent as a hybrid entity needs to be carefully applied, as it can have significantly different density, permeability, and meanings at various points of the patent network. The patent network appears to be quite hybrid during the patent drafting process. I have shown that it is less so when inventions are routed as documents in the patent administration according to their classification. After scientific inventions become eclipsed by their legal reconstruction as written claims, it is their classification as files that creates the material network by which these textual inscriptions are interpreted, routed, and acted upon. It is precisely the internalist nature of patent classification which allows us to trail the bureaucratic paper and electronic trails of legal inventive novelty.

Lastly, in what sense is such a "reality" based on the legal modeling of its own semantic constructs real? The problem with the legal form of representation and its constitutive practices arises when they are applied across different spheres: "The concept of reality only makes sense within a context of replication, and it only becomes a problem when alternative systems of representation come into play" (Rheinberger 1997, 113). The same problematization also holds for representation: "The problem of representation arises as a function of analytic efforts to assign stable sense and value to structures of practical action that, in the interest of analysis, have first been dissociated from the particular occasions in which they are used" (Lynch 1994, 146). From a purely internal legal perspective, the self-referential making of the new patent class may make practical sense; however, it starts to become problematic from a technological and scientific standpoint as the remit of the patent classification also affects other social contexts. The IPC lends solidity to the representation of invention in patent documents, organizes their routing and the very structure of patent bureaucracy, and thus mobilizes their circulation across several social domains (Vismann [2001] 2008; Latour 2002; Riles 2006). As such, the legal representation of inventions by patent documents and their stabilization by patent classification are inherently fraught with problems.

\section{Acknowledgments}

Research for this paper was supported by a postdoctoral fellowship at the Max Planck Institute for the History of Science. I owe special debt to Hans-Jörg Rheinberger for welcoming a legal scholar into his department and for his support during the fellowship. I am grateful to Christoph Hoffmann, Ursula Klein, Maria Kronfeldner, Alexandre Métraux, as well as the two reviewers, for their comments and criticism. I owe intellectual debt to Alain Pottage for conversations about patents. For clarification 
on the IPC working group process, I thank Heiko Wongel at the European Patent Office and Martin Price at the UK Patent Office; for insights into patent search practice, I thank Bengt Jonsson, patent searcher at WPT, and Jae Park, patent associate at Venner Shipley.

\section{References}

Adams, Stephen R. 2006. Information Sources in Patents. Munich: K. G. Saur.

Albrecht, Miguel, et al. 2010. "Quality Assurance in the EPO Patent Information Resource." World Patent Information 32(4):279-286.

Bachelard, Gaston. [1934] 1988. Der neue wissenschaftliche Geist, translated into German by Michael Bischoff. Frankfurt am Main: Suhrkamp.

Baker, Wendy, et al. 2000. "The EMBL Nucleotide Sequence Database.” Nucleic Acids Research 28(1):1923.

Barnes, Barry, David Bloor, and John Henry. 1996. Scientific Knowledge: A Sociological Analysis. London: Athlone Press.

Biagioli, Mario. 2006. "Patent Republic: Representing Inventions, Constructing Rights and Authors." Social Research 73(4):1129-1172.

Bloor, David. 1982. "Durkheim and Mauss Revisited: Classification and the Sociology of Knowledge." Studies in History and Philosophy of Science 13(4):267-297.

Bonino, Dario, et al. 2010. "Review of the state-of-the-art in patent information and forthcoming evolutions in intelligent patent informatics." World Patent Information 32(1):30-38.

Bostanci, Adam, and Jane Calvert. 2008. "Invisible Genomes: The Genomics Revolution and Patenting Practice." Studies in History and Philosophy of Biological and Biomedical Sciences 39:109-19.

Bowker, Geoffrey. 1992. "What's in a Patent?" In Shaping Technology/Building Society: Studies in Sociotechnical Change, edited by Wiebe E. Bijker and John Law, 53-74. Cambridge MA: MIT Press.

Bracha, Oren. 2005. "Owning Ideas: A History of Anglo-American Intellectual Property." S.J.D. diss. Harvard Law School.

Brennan, David. J. 2005. "The Evolution of English Patent Claims as Property Definers." Intellectual Property Quarterly 4:361-99.

Burk, Dan L., and Mark A. Lemley. 2005. "Quantum Patent Mechanics." Lewis E Clark Law Review 9:29. Available at SSRN: http://ssrn.com/abstract $=628224$.

Cambrosio, Alberto, Peter Keating, and Michael McKenzie. 1990. "Scientific Practice in the Courtroom: The Construction of Sociotechnical Identities in a Biotechnology Patent Dispute." Social Problems 37(3):275-293.

Czarnik, Anthony. 1999. "Editorial." Journal of Combinatorial Chemistry 1(1):1-2.

Cullen, Susan E. 2009. "A practical approach to the reformed IPC.” World Patent Information 31(3):193-98.

Daston, Lorraine. 2000. "The Coming into Being of Scientific Objects." In Biographies of Scientific Objects, edited by Lorraine Daston, 1-14. Chicago: University of Chicago Press.

Derrida, Jacques. [1987] 2007. Psyche: inventions de l'autre. Paris: Editions Galilée.

Desrosières, Alain. 1990. "How to Make Things which Hold Together: Social Science, Statistics and the State." In Discourses on Society: The Shaping of the Social Science Disciplines, edited by Peter Wagner, Björn Wittrock, and Richard Whitley, 195-218. London: Kluwer.

Dirnberger, Dietmar. 2011. "A guide to efficient keyword, sequence and classification search strategies for biopharmaceutical drug-centric patent landscape searches.” World Patent Information 33(2):128-143.

Douglas, Mary. [1966] 1991. Purity and Danger. London: Routledge and Kegan Paul.

Douglas, Mary, and David Hull, eds. 1992. How Classification Works: Nelson Goodman among the Social Sciences. Edinburgh: Edinburgh University Press. 
Dubaric, Ervin, Dimitris Giannoccaro, Rune Bengtsson, and Thomas Ackermann. 2011. "Patent data as indicators of wind power technology development." World Patent Information 33(2):144-149.

Durkheim, Emile, and Marcel Mauss. [1903] 1963. Primitive Classification. Translated from the French and edited with an introduction by Rodney Needham. Chicago: University of Chicago Press.

Edmond, Gary. 2001. "The Law-Set: The Legal-Scientific Production of Medical Propriety." Science, Technology, and Human Values 26:192.

Eisenberg, Rebecca. 2002. "Molecules vs. Information: Should Patents Protect Both?" Boston University Journal of Science and Technology Law 8:190.

Eisenberg, Rebecca. 2006. "Biotech patents: looking backwards while moving forward." Nature Biotechnology 24(3):317-19.

Eisenberg, Rebecca, and Arti K. Rai. 2003. "Bayh-Dole Reform and the Progress of Biomedicine." Law and Contemporary Problems 66:289-313.

European Bioinformatics Institute. 1998. EMBL Nucleotide Sequence Database Release Note 58, March.

European Bioinformatics Institute. 2012. EMBL Nucleotide Sequence Database Release Note 111, March. http://www.ebi.ac.uk/embl/Documentation/Release_notes/current/relnotes.html (last accessed April 1, 2012).

European Patent Office. 2011. Moving towards a Global Patent System. http://www.epo.org/papers/ classification-ip5/index.html\#/0 (last accessed January 30, 2012).

European Patent Office. 2012. "Patent Statics for Decision Making." Patent Information News 1:6. http://www.epo.org/service-support/publications/patent-information/news/2012.html (last accessed February 29, 2012).

Foglia, Pasquale. 2008. "Use of Classification at the EPO," Presentation at the WIPO IPC Workshop, 5 February.

Foucault, Michel. [1966] 1990. The Order of Things. New York: Vintage Books.

Geysen, Mario H., et al. 1996. "Isotope or Mass Encoding of Combinatorial Libraries." Chemistry and Biology 3:679-688.

Geysen, Mario H., et al. 2003. "Combinatorial Compound Libraries for Drug Discovery: An Ongoing Challenge." Nature Reviews Drug Discovery 2(3):222.

Gibbs, W. Wayt. 2001. "Patently Inefficient." Scientific American 284(2):23-4.

Gieryn, Thomas F. 1983. "Boundary-Work and the Demarcation of Science from Non- Science: Strains and Interests in Professional Ideologies of Scientists." American Sociological Review 48(6):781-95.

Goodman, Nelson. 1968. Languages of Art. Indianapolis: Bobbs-Merrill.

Goodman, Nelson. 1978. Ways of Worldmaking. Indianapolis: Hackett.

Hilgartner, Stephen. 1998. "Data Access in Genome Research." In Private Science: Biotechnology and the Rise of Molecular Sciences, edited by Arnold Thackray, 202-18. Philadelphia: University of Pennsylvania Press.

Jasanoff, Sheila, ed. 2003. States of Knowledge: The Co-Production of Science and Social Order. London: Routledge.

Jordan, Kathleen, and Michael Lynch. 1998. "The Dissemination, Standardization and Routinization of a Molecular Biological Technique." Social Studies of Science 28(5-6):773-800.

Kang, Hyo Yoon. 2006. "Invention and Agency in Patent Law." Paper presented at the Conference "Con/Texts of Inventions," April 20-23, at Case Western Reserve University in Cleveland OH.

Kenney, Martin. 1986. Biotechnology: The University-Industrial Complex. New Haven: Yale University Press.

Kenney, Martin. 1998. "Biotechnology and the Creation of a New Economic Space." In Private Science: Biotechnology and the Rise of Molecular Sciences, edited by Arnold Thackray, 131-143. Philadelphia: University of Pennsylvania Press.

Kevles, Daniel J. 1994. "Ananda Chakrabarty Wins a Patent." Historical Studies in the Physical and Biological Sciences 25:111-136.

Kinnan, William. 1920. "Progress of the Patent Reclassification Work." Journal of the Patent Office Society 2(7):332-337. 
Kuhn, Thomas. 1970. The Structure of Scientific Revolutions. Chicago: University of Chicago Press.

Latour, Bruno. 1999. Pandora's Hope. Cambridge MA: Harvard University Press.

Latour, Bruno. 2002. La Fabrique du droit. Une ethnographie du Conseil d’Etat. Paris: La Découverte.

Lenoir, Tim and Eric Giannella. 2006. "The Emergence and Diffusion of DNA Microarray Technology." Journal of Biomedical Discovery and Collaborations 1(1):11.

Li et al. 2010. "Non-redundant patent sequence databases with value-added annotations at two levels." Nucleic Acids Research 38:D52-D56.

Lynch, Michael. 1994. "Representation is Overrated: Some Critical Remarks about the Use of the Concept of Representation in Science Studies." Configurations 2:137-49.

MacLeod, Christine. 1988. Inventing the Industrial Revolution: The English Patent System 1660-1800. Cambridge: Cambridge University Press.

Merrifield, Bruce. 1963. "Solid Phase Peptide Synthesis. The synthesis of a tetrapeptide." Journal of American Chemical Society 85:2149-54.

Mirowski, Philip. 2011. Science-Mart: Privatizing American Science. Cambridge MA: Harvard University Press.

Müller-Wille, Staffan, and Hans-Jörg Rheinberger. 2009. Das Gen im Zeitalter der Postgenomik. Eine wissenschaftliche Bestandsaufnahme. Frankfurt am Main: Suhrkamp.

Myers, Gregg. 1995. "From Discovery to Invention: The Writing and Rewriting of Two Patents." Social Studies of Science 25(1):57-105.

Nicolaou, K.C., Rudolf Hanko, and Wolfgang Hartwig. 2002. "Combinatorial Chemistry in Perspective." In Handbook of Combinatorial Chemistry, edited by K.C. Nicolaou, Rudolf Hanko, and Wolfgang Hartwig, 1-8. Weinheim: Wiley-VCH.

Nowak, Rachel. 1995. "Entering the Postgenome Era." Science 270(5235):368-71.

Nowotarski, Mark, Arlene Zank, and Michael Bowman. 2011. "Increasing patent allowance rates by selectively targeting a more technological patent class." IP Watchdog 6 April 2011. http://www.ipwatchdog. com/2011/04/06/increasing-allowance-rates-by-selectively-targeting-patent-class/id=16283/ (last accessed March 19, 2012).

Parry, Bronwyn. 2004. Trading the Genome: Investigating the Commodification of Bio-Information. New York: Columbia University Press.

PatVal-EU Project. 2005. The Value of European Patents. Evidence from a Survey of European Inventors. Final report. http://ec.europa.eu/invest-in-research/pdf/download_en/patval_mainreportandannexes.pdf (last accessed February 23, 2012).

Pila, Justine. 2003. "Bound Futures: Patent Law and Modern Biotechnology." Boston University Journal of Science and Technology Law 9(2):326-378.

Pottage, Alain. 1998. "The Inscription of Life in Law: Genes, Patents and Biopolitics." Modern Law Review 61(5):740-65.

Pottage, Alain. 2006. "Materialities in Life and Law: Informatic Technologies and Industrial Property." Paragrana 15(1):82-101.

Pottage, Alain, and Brad Sherman. 2007. "Organisms and manufactures: on the history of plant inventions." Melbourne University Law Review 31(2):539-568.

Pottage, Alain, and Brad Sherman. 2010. Figures of Inventions. A History of Modern Patent Law. Oxford University Press.

Quinn, Gene. 2012. "Business methods by the numbers: A look inside PTO class 705." IP Watchdog 22 January 2012. http://www.ipwatchdog.com/2012/01/22/business-methods-by-the-numbers-a-lookinside-pto-class-705/id=21892/ (last accessed March 19, 2012).

Rabinow, Paul. 1996. Making PCR: A Story of Biotechnology. Chicago: University of Chicago Press.

Rai, Arti K. 1999. "Regulating Scientific Research: Intellectual Property Rights and the Norms of Science." Northwestern University Law Review 94(1):77-152.

Rampelmann, Juergen. 1996. "Classification Tools at the EPO.” World Patent Information 18(3):149153. 
Rampelmann, Juergen. 1999. "Classification and the future of the IPC - the EPO view." World Patent Information 21(3):183-90.

Rankin, William. 2006. "Bureaucracy at a Glance: Visual Evidence and US Patents, 1790-2005." Paper presented at the Conference "Con/Texts of Inventions," April 20-23, at Case Western Reserve University in Cleveland $\mathrm{OH}$.

Rheinberger, Hans-Jörg. 1997. Toward a History of Epistemic Things. Synthesizing Proteins in a Test Tube. Stanford CA: Stanford University Press.

Riardan, Teresa. 2002. "Patent Model's Strange Odyssey." New York Times 18 February. http://www. nytimes.com/2002/02/18/business/18PATE.html (last accessed March 2, 2010).

Riles, Annelise. 2001. The Network Inside Out. Ann Arbor: University of Michigan Press.

Riles, Annelise. 2006. Documents: Artifacts of Modern Knowledge. Ann Arbor: University of Michigan Press.

Rossman, Joseph. 1933. "Editor's Page: Proper Classification of Patents Is Vital." Journal of the Patent Office Society 15(1):3-4.

Rossman, Joseph. 1934. “Editor's Page: Emergency Funds of the Patent Office Classification Work.”Journal of Patent Office Society 16(1):3-4.

Rouse, Richard and Gary Hardiman. 2003. "Microarray technology - an intellectual property retrospective." Pharmacogenomics 4(5):623-32.

Schmoch, Ulrich. 2008. "Concept of a Technology Classification for Country Comparisons. Final Report to the WIPO," IPC/CE/41/5 Annex.

Sherman, Brad. 1994. "Governing Science: Patents and Public Sector Research." Science in Context 7(3):515-538.

Sherman, Brad. 2008. "Taxonomic Property." Cambridge Law Journal 67(3):560-584.

Sherman, Brad, and Lionel Bently. 1999. The Making of Modern Intellectual Property Law: The British Experience, 1760-1911. Cambridge: Cambridge University Press.

Star, Susan Leigh, and Geoffrey Bowker. 1999. Sorting Things Out. Classification and Its Consequences. Cambridge MA: MIT Press.

Strathern, Marilyn. 1988. The Gender of the Gift. Berkeley: University of California Press.

Strathern, Marilyn. 1996. "Cutting the Network." Journal of the Royal Anthropological Institute 2(3):517-35.

Sunder Rajan, Kaushik. 2006. Biocapital. Durham and London: Duke University Press.

Swanson, Kara. 2007. "Biotech in Court: A Legal Lesson on the Unity of Science." Social Studies of Science 37(3):357-84.

Swanson, Kara. 2009. "The Emergence of the Professional Patent Practitioner." Technology and Culture 50:519-48

Swanton, Frederick W. 1922. "Paper Files and Binders, Indexing and Related Arts." Journal of the Patent Office Society 4(10):467.

Swedish Patent and Registration Office. 2011. "Active Development of the Patent Classification Systems." http://www.prv.se/en/About-us/News/Active-development-of-the-patent-classificationsystems/ (last accessed December 17, 2011).

Symyx. 1999. SEC Form 424B4 Prospectus filed pursuant to Rule 421, 18 November 1999. http:// investor.symyx.com/sec.cfm (last accessed February 19, 2009).

te Heesen, Anke. 2000. patent. eine ausstellung mit 12 objekten. Catalogue leaflet for an exhibition of patent models organized at the Max Planck Institute for the History of Science, Berlin.

Terrett, Nicholas. 1998. Combinatorial Chemistry. Oxford: Oxford University Press.

Thackray, Arnold, ed. 1998. Private Science: Biotechnology and the Rise of Molecular Sciences. Philadelphia: University of Pennsylvania Press.

Van Dulken, Stephen, ed. 1998. Introduction to Patents Information. British Library.

Van Thielen, J. 1998. "Online classification and indexation of documents at the EPO." World Patent Information 20(1):17-20.

Vismann, Cornelia. [2001] 2008. Files: Law and Media Technology. Stanford: Stanford University Press. WIPO. 1997. Introduction to Intellectual Property Theory and Practice. London, The Hague, Boston: Kluwer Law International. 
Wittgenstein, Ludwig. [1958] 1991. Philosophical Investigations. Malden MA and Oxford: Wiley-Blackwell.

Wolter, Bernd. 2012. "It takes all kinds to make a world - some thoughts on the use of classification in patent searching. World Patent Information 34(1):8-18.

Wright, Susan. 1986. "Recombinant DNA Technology and Its Social Transformation, 1972-1982." Osiris 2(2):303-60.

Wyman, William. 1922. "The Filing Equipment of the Patent Office." Journal of the Patent Office Society 5(4):60-69.

\section{Legal Material}

EPO, European Patent Convention. [1973] revised 2000.

EPO. [1973] amended 2001. Implementing Regulations to the Convention on the Grant of European Patents, EP002EN.

EPO. 1998. Organisation of Search and Documentation in DG1. Munich: The Hague.

EPO. 2010. Guidelines for Examination in the European Patent Office. http://www.epo.org/law-practice/ legal-texts/html/guiex/e/index.htm (last accessed April 22, 2012).

EPO and USPTO Cooperative Patent Classification Implementation Group. 2011. Cooperative Patent Classificaiton (CPC). EPO and USPTO Bilateral Classification System. http://www. cooperativepatentclassification.org/publications/CPCPresentation.pdf (last accessed January 19, 2012)

WIPO, Budapest Treaty on the International Recognition of the Deposit of Microorganisms for the Purposes of Patent Procedure. [1977] amended 1980. 32 U.S.T. 1241, 1861 U.N.T.S. 361.

WIPO, Strasbourg Agreement Concerning International Patent Classification. 1971. WO026EN.

WIPO. 1995. Introductory Manual to the IPC, HE050103.

WIPO. 1999-2012. IPC Union Committee of Experts Reports and Annexes (IPC/CE/28 - IPC/CE/44). http://www.wipo.int/meetings/en/topic.jsp?group_id=115 (last accessed April 15, 2012).

WIPO. 2000-2004. Revision Project IPC/C422 Annex 1 - 92, available at IPC e-forum. http:// www.wipo.int/ipc-ief/en/project/13/C422 (last accessed April 10, 2012).

WIPO. 2006. Guide to the IPC (Int.Cl. [8th edition] vol. 5, Guide), WIPO Publication No. 560E5/8.

WIPO. 2007. "Publication of the Ninth Edition of the IPC (IPC-2009) and Related Material." IPC Revision Working Group Eighteenth Session, 1 October (IPC/WG/18/2).

WIPO. 2008a. Guide to the IPC (IntCl. [9 ${ }^{\text {th }}$ edition]). http://www.wipo.int/classifications/ipc/en/guide/ guide_ipc_2009.pdf (last accessed April 22, 2012).

WIPO. 2008b. PCT - The International Patent System. Yearly Review. Developments and Performance in 2008. http://www.wipo.int/export/sites/www/ipstats/en/statistics/pct/pdf/yearly_review_09.pdf (last accessed April 4, 2010).

WIPO. Simplified Revision Policy and Revision Procedure for the Reformed IPC. http://www.wipo. int/classifications/ipc/en/simplification/simplification_revision_publication.html (last accessed April 22, 2012).

WIPO. 2012. Comments on Improving the IPC E-Forum Project CE445. http://www.wipo.int/ipcief/en/project/1539/CE445 (last accessed April 10, 2012).

USPTO. 2005. Handbook of Classification. http://www.uspto.gov/web/offices/opc/documents/handbook. pdf (last accessed April 22, 2012).

USPTO. [2001] 2010. Manual of Patent Examining Procedure $8^{\text {th }}$ ed. http://www.uspto.gov/web/ offices/pac/mpep/index.htm (last accessed April 15, 2012).

USPTO. 2009. Overview of the U.S. Patent Classification System. http://www.uspto.gov/web/offices/ opc/documents/overview.pdf (last accessed April 22, 2012).

United States Patent Act. 1836. Ch. 357, 5 Stat. 117. http://www.ipmall.info/hosted_resources/lipa/ patents/Patent_Act_of_1836.pdf (last accessed April 12, 2012).

United States Patent Act. 1952. 35 USCS Sect. 1-376. http://www.uspto.gov/web/offices/pac/ mpep/consolidated_laws.pdf (last accessed August 12, 2012). 


\section{Cases Cited}

Diamond v. Chakrabarty 447 U.S. 303 (1980)

Howard Florey/Relaxin T74/91 [1995] EPOR 541

Harvard/Onco-mouse [2003] OJEPO 473

In re Argoudelis 168 U.S.P.Q. (BNA) 99 (C.C.P.A. 1970)

Kirin Amgen [2002] RPC 187

Seed $v$ Higgins (1858) 8 El \& Bl 755; 120 ER 281 (Queens Bench); Higgins v Seed (1858) 8 El \& Bl 771,

120 ER 287 (Exchequer); Seed v Higgins (1860) 8 HLC 550; 11 ER 544 (House of Lords).

State Street Bank v. Signature Financial Group 47 USPQ2d 1596 (Fed.Cir. 1998). 